\title{
La importancia de decolonizar el derecho internacional de los derechos humanos: el caso de la consulta previa en Colombia**
}

\section{The importance of decolonizing International Human Rights Law: The prior consultation in Colombia case}

RESUMEN

La consulta previa ha sido reconocida como uno de los instrumentos más emacipatorios en el marco del derecho internacional de los derechos humanos, con el que cuentan los pueblos indígenas y las comunidades étnicas para

Visiting Fellow del Centre for Critical International Law CeCIL, Kent Law School, University of Kent (2015-2016); Visiting Fellow del Transnational Law Institute (TLI), The Dickson Poon School of Law, King's College London (2015); becaria doctoral Colciencias (2012-2016) y candidata a doctora de la Universidad del Rosario; magíster en Sociología Jurídica de la Universidad Nacional de La Plata (Argentina); abogada de la Universidad Externado de Colombia; alumni 2014 del Institute for Global Law and Policy IglP, Harvard Law School, the Workshop 2014 (Doha, Qatar) y alumni del mismo Instituto, en the African Workshop 2016 (Cape Town, South Africa). Se ha desempeñado como docente de Derecho Internacional, Derechos Humanos y Derecho Internacional Humanitario, Ambiente y Desarrollo, Argumentación y Hermenéutica Jurídicas, Cine y Derechos Humanos, inter alia. Ha sido abogada en la Comisión Colombiana de Juristas y la Coalición contra la Vinculación de Niñas, Niños y Jóvenes al Conflicto Armado en Colombia y en la Defensoría Delegada para los Derechos de la Mujer, la Niñez y la Juventud. Contacto: jimenasierra@gmail.com

Una versión previa de este artículo fue presentada en la conferencia "Third World Approaches to International. On Praxis and the Intellectual" que se llevó a cabo en The American University of Cairo (El Cairo, Egipto) entre el 21 y el 24 de febrero de 2015; así como en el Workshop auspiciado por Windsor University, que tuvo lugar en Windsor University (Windsor, Canadá) entre el 6 y el 8 de junio de 2015. Quiero agradecer a Windsor University y al Institute for Global Law and Policy (IGLP) por su apoyo. Asimismo, quiero extender mi especial agradecimiento, por sus comentarios y lecturas a borradores y versiones previas de este artículo, a los profesores y colegas William Conklin, Sujith Xavier, Usha Natarajan, John Reynolds, Tyler McCreary, Laura Gutiérrez-Escobar y, especialmente, a Amar Bhatia. Las limitaciones de este artículo son solo mías.

Recibido el 31 de enero de 2017, aprobado el 19 de abril de 2017.

Para citar el artículo: SiERRA-CAMARGo, J. La importancia de decolonizar el derecho internacional de los derechos humanos: el caso de la consulta previa en Colombia. Derecho del Estado n. ${ }^{\circ}$ 39, Universidad Externado de Colombia, julio-diciembre de 2017, pp. 137-186. DOI: https://doi.org/10.18601/01229893.n39.07 
defender sus territorios en la actualidad. Sin embargo, la consulta previa también ha tenido en algunos casos un uso ambivalente por diversos actores que han acudido a este instrumento para fines diferentes a los contemplados en el Convenio 169 de la oIT, uso que, lejos de proteger los derechos de los pueblos y comunidades, ha redundado en su afectación y en el detrimento de estos grupos. El propósito principal de este artículo es cuestionar el uso ambivalente de la consulta previa en Colombia desde la perspectiva del pensamiento decolonial, partiendo de la noción de la 'colonialidad'. Específicamente se argumenta que el problema de las restricciones y limitaciones de la consulta que se explican en este artículo obedece a los sesgos coloniales que arrastra la consulta y que a su vez se encuentran imbuidos en la lógica liberal a la que responde dicha institución.

PALABRAS CLAVE

Consulta previa, ambivalencia, crítica decolonial, colonialidad, paradoja inclusión/exclusión.

\section{ABSTRACT}

Prior consultation has been recognized as one of the most emancipatory instruments within the framework of international human rights law, which currently allows indigenous peoples and ethnic communities defend their territories. Nevertheless, in some cases the prior consultation has had an ambivalent use by other agents who have used this instrument for different purposes than those stated in ILO Convention 169 and that have caused serious damages on these groups. In this sense, the main purpose of this article is to question the ambivalent use of prior consultation in Colombia from the perspective of 'decolonial thinking', and in particular, from the notion of 'coloniality'. I argue that the problem of the restrictions and limitations of the prior consultation described in this article is due to the colonial bias of this instrument, which in turn is embedded in a liberal rationality.

KEYWORDS

Prior consultation, ambivalence, decolonial critique, coloniality, the inclusion/ exclusion paradox. 
SUMARIO

Introducción: el problema de la ambivalencia de la consulta previa en Colombia. 1. Un breve resumen de los estándares de la consulta previa en Colombia. 2. El uso ambivalente de la consulta previa en Colombia: tres casos emblemáticos. 3. Repensar la consulta previa desde una perspectiva decolonial. Conclusión: la importancia de decolonizar la consulta previa en Colombia. Referencias.

Este es, amigos, el nudo de nuestra soledad [...]. Es comprensible que insistan en medirnos con la misma vara con que se miden a símismos, sin recordar que los estragos de la vida no son iguales para todos, y que la búsqueda de la identidad propia es tan ardua y sangrienta para nosotros como lo fue para ellos.

La interpretación de nuestra realidad con esquemas ajenos sólo contribuye a hacernos cada vez más desconocidos, cada vez menos libres, cada vez más solitarios. Tal vez la Europa venerable sería más comprensiva si tratara de vernos en su propio pasado.

Gabriel García Márquez

Discurso de recepción del Premio Nobel de Literatura 8 de diciembre de 1982, Estocolmo (Suecia)

\section{INTRODUCCIÓN: EL PROBLEMA DE LA AMBIVALENCIA}

DE LA CONSULTA PREVIA EN COLOMBIA

El derecho internacional de los derechos humanos (en adelante, DIDDHH) es reconocido como una de las instituciones jurídico-políticas más importantes de la modernidad por su carácter emancipatorio. Sin embargo, este conjunto de normas también arrastra un profundo sesgo colonial. Los orígenes europeo-occidentales del DIDDHH han impregnado a este derecho de un sello que responde a una mirada del mundo profundamente eurocéntrica. Esta mirada tiende a inhibir la capacidad de imaginar 'otros' mundos posibles que difieren de una forma de vida que se presenta como única y que a su vez responde a las condiciones prácticas y legales que impone una racionalidad económica dominante.

Los usos que se la han dado por parte de algunos actores a la consulta previa son un ejemplo de las restricciones que conlleva el DIDDHH, como consecuencia de las continuidades del pensamiento colonial, que a su vez se encuentran imbuidas en una visión liberal. En efecto, la consulta previa suele ser percibida como una de las instituciones más emancipatorias en el marco del DIDDHH, en la medida que tiene como propósito incluir en la toma de decisiones que implican la afectación de territorios ancestrales a pueblos y comunidades étnicas que han sido discriminadas históricamente. 
Sin embargo, tal como se explica en este artículo, la consulta previa también ha sido utilizada en algunos casos como un instrumento de exclusión de las comunidades indígenas y de los pueblos étnicos. Esto obedece en parte a que la lógica de la visión liberal del mundo en la que se encuentra enmarcada la consulta conlleva serias limitaciones en su propósito de 'incluir' en una sociedad democrática y pluralista otras formas de vida diferentes a la forma de vida 'occidental'.

Esta ambivalencia de la consulta previa ha sido explicada por Roger Merino bajo la paradoja de la 'inclusión/exclusión'. Según este autor, esta paradoja opera en el cuadro del llamado (neo)colonialismo, donde en el marco del Estado de derecho las comunidades y pueblos indígenas solo son reconocidos como 'minorías' étnicas dentro de la idea de una nación mayoritaria y dominante, que a su vez implica la negación de aspiraciones jurídicas y políticas de estos grupos sobre la forma de relacionarse con sus territorios. $\mathrm{Al}$ respecto, Merino afirma:

... en la negación colonial de dos aspectos clave de la legalidad y la política indígenas: la negación de sus territorios y de la tenencia comunal y la negación de su carácter de naciones (por lo que fueron concebidos como minorías étnicas dentro de una nación dominante). El nuevo colonialismo oscila en un rango que va desde la exclusión abierta tanto material como jurídica, hasta una sutil inclusión en términos jurídicos y políticos. Esta paradoja (de exclusión/inclusión) permanece así en los actuales intentos de eliminar la tenencia comunal indígena de la tierra mediante el reconocimiento de la propiedad privada en parcelas específicas, así como en la aplicación del estado de excepción frente a protestas masivas o en la explotación de territorios indígenas en nombre del interés general ${ }^{1}$ (trad. mía).

Según este autor, a través de instituciones como la 'propiedad privada', la consulta previa, la declaración de áreas como parques o reservas naturales, los pueblos y comunidades indígenas se ven obligados a mantener una relación ambigua con la 'legalidad liberal'. Bajo la premisa de estos grupos que reza "a problema de blanco, solución de blanco", los pueblos y comunidades terminan valiéndose de las instituciones propias del derecho occidental moderno, como la consulta, para defender su territorio, pero al mismo tiempo se ven expuestos a las limitaciones y restricciones de tales instituciones por la manera que tienen estos grupos de relacionarse con su territorio de acuerdo a su modo de ver y de entender el mundo. Es en este sentido que Merino afirma que "la lucha de los pueblos indígenas por su autodeterminación y por su emancipación social mediante la apropiación de la legalidad liberal y

1 Merino, R. Coloniality and Indigenous Territorial Rights in the Peruvian Amazon: A Critique of the Prior Consultation Law. (2015) 38 Bath Papers in International Development and Wellbeing Centre for Development Studies, University of Bath, 2. Disponible en: http://www. bath.ac.uk/cds/publications/bpd38.pdf 
yendo más allá de esta, devela la disputa de la lógica de la legalidad liberal de inclusión o de exclusión"2 (trad. mía).

Poner en evidencia el uso ambivalente de la consulta previa implica cuestionar el alcance emancipatorio de dicha institución y preguntarse si a través de ella es posible avanzar en un efectivo proceso de decolonización o si, por el contrario, la consulta está concebida simplemente como un instrumento de persuasión del pensamiento liberal, que implica un ambiguo consenso bajo la retórica del discurso de la gobernanza global, que a la larga termina perpetuando poderosas ideas propias de la lógica colonial como la idea de la 'dominación pacífica' 3 .

En este sentido, también es importante precisar que aunque la visión liberal del mundo se presenta a sí misma como una antítesis del pensamiento colonial, a través de diversas instituciones de raigambre liberal se ha podido dar continuidad a legados coloniales, que terminan siendo aceptados y reproducidos a través de la enseñanza del DIDDHH e incorporadas en el ejercicio de la profesión jurídica tanto por los jueces como por los operadores jurídicos.

Para analizar el problema que se plantea sobre la ambivalencia de la consulta previa desde esta perspectiva, resulta fundamental remitirnos al pensamiento decolonial, y de manera particular a la crítica que han desarrollado algunos de sus autores sobre la idea de la modernidad y de sus instituciones. Al respecto, Ramón Grosfoguel afirma que "la modernidad y la colonialidad son dos caras de la misma moneda" colonialidad; resaltando con ello que la constitución colonial del mundo y la continuación de la relación de interdependencia modernidad/colonialidad es lo que permite que algunos de los legados coloniales se mantengan aun dos siglos después de eliminarse formalmente las administraciones coloniales, y después de los procesos de descolonización que tuvieron lugar en la segunda mitad del siglo $\mathrm{xx}$.

Esta perspectiva hace énfasis, por un lado, en las continuidades históricas entre los tiempos coloniales y (pos)coloniales, y por otro lado, en las dimensión epistémica de las relaciones asimétricas que persisten entre los llamados Estados de 'centro' y los Estados 'periféricos' o 'semi-periféricos', en donde estaban asentadas antiguamente las administraciones coloniales.

2 Ibíd.

3 Walter Mignolo ha llamado la atención sobre el hecho de que Fray Bartolomé de Las Casas rechazó por un lado la violencia física en contra de los indígenas, bajo la idea del 'derecho natural', pero por otro lado apoyó la evangelización por medios 'pacíficos' de los mismos. Sobre este punto, Mignolo se cuestiona sobre el carácter pacífico con que se promovieron las acciones de evangelización de los indígenas, argumentando que tales acciones en realidad constituyeron otra forma de violencia, y de manera más específica, una forma de 'violencia epistémica'. Véase Mignolo, W. (ed.). Historias locales/diseños globales. Madrid: Akal, 2003.

4 Grosfoguel, R. La descolonización de la Economía Política y los Estudios Postcoloniales: transmodernidad, pensamiento fronterizo y colonialidad global. Tabula Rasa. 4 (2006) 27. 
De acuerdo al pensamiento decolonial, esas relaciones terminan por definir las categorías centrales y quiénes son los referentes de centro, a la vez que determinan quiénes ocupan el lugar de sujetos 'subalternos'.

Así, tal como lo afirma Julieta Lemaitre, mientras bajo la noción liberal del 'multiculturalismo' se niega la violencia de la conquista como una tragedia irresoluble y se reconoce a las comunidades y pueblos indígenas como los 'otros' y como 'sujetos de derecho', siempre que aquellos cumplan con ciertas condiciones impuestas por el orden legal "mayoritario' ${ }^{5}$, otras aproximaciones al problema de la ambivalencia que se plantea, como lo es el pensamiento decolonial, resaltan la violencia de los tiempos coloniales para explicar las restricciones, limitaciones y contradicciones de la modernidad.

Según Héctor Alimonda, el trauma catastrófico de la conquista y el proceso a través del cual las antiguas fueron integradas al sistema inter-nacional son la marca de origen del continente latinoamericano. Es a partir de ello que Alimonda explica su idea de que la colonialidad es el necesario y 'oculto' reverso de la modernidad. Sin embargo, este autor también aclara que lo anterior no significa que el destino de los pueblos latinoamericanos esté determinado fatalmente por este suceso, sino que es necesario reconocer la importancia de esa marca en el desarrollo de las sociedades en el mundo colonial y (pos) colonial ${ }^{6}$.

Ahora bien, cuestionar el alcance emancipatorio de la consulta previa desde esta perspectiva nos puede permitir explicar en qué medida las limitaciones que conlleva la consulta se explican por el sesgo colonial que arrastra la lógica liberal en la que se encuentra imbuida dicha institución.

Dicho lo anterior, en este artículo se presenta en primer lugar una síntesis de los estándares normativos de la consulta previa en Colombia. Segundo, se exponen tres casos emblemáticos que muestran las restricciones y limitaciones que ha tenido la consulta previa en el contexto colombiano y que ponen de presente su carácter 'ambivalente'. Tercero, se explica en qué medida las limitaciones del alcance de la consulta previa implican la continuidad de legados coloniales a través de instituciones de raigambre liberal. En esta parte se analiza específicamente cómo la consulta previa ha sido utilizada como un mecanismo de 'dominación pacífica', así como la relación de este uso que se le ha dado a la consulta con el pasado colonial. Para ello, me apoyo principalmente en el planteamiento de algunos autores del pensamiento decolonial, en diálogo con otros autores de la corriente denominada Aproximaciones Críticas al Derecho Internacional (en inglés, Third World Approaches to International Law, o TWAIL). Por último, como

5 Lemaitre Ripoll, J. El derecho como conjuro. Fetichismo legal. Violencia y movimientos sociales. Bogotá: Siglo del Hombre Editores, 2009, 302.

6 Alimonda, H. Una introducción a la ecología política. En Lugares decoloniales. Espacios de intervención en las Américas. Bogotá: Universidad Javeriana, 2012, 59-94. 
posible respuesta al problema que se plantea, se abre un interrogante sobre la posibilidad de decolonizar el uso de la consulta previa a partir de la incorporación de la idea del 'pluri-verso"7 en lugar de la idea del 'uni-verso' o de la 'uni-versalidad' del DIDDHH, esto para crear en las narrativas del derecho moderno otros mundos posibles.

\section{UN BREVE RESUMEN DE LOS ESTÁNDARES NORMATIVOS DE LA CONSULTA PREVIA EN COLOMBIA}

El Convenio 169 de la Organización Internacional del Trabajo (OIT) es el instrumento que regula en el ámbito internacional la consulta previa, y fue incorporado al ordenamiento jurídico colombiano por medio de la Ley 21 de 1991. Asimismo, en la sentencia C-864 de 2008 la Corte Constitucional de Colombia señaló expresamente que dicho Convenio hace parte del bloque de constitucionalidad ${ }^{8}$.

Tal como se indicó en líneas anteriores, el propósito principal del Convenio 169 de la OIT es consagrar el deber de las autoridades nacionales de consultar a los pueblos indígenas y tribales, entre los que se incluyen las comunidades afrodescendientes -negras, palenqueras y raizales- en el caso de Colombia, cuando se prevean medidas administrativas o legislativas que puedan afectarlos directamente ${ }^{9}$. En este sentido, lo que se busca primordialmente con la consulta previa es garantizar la participación de los pueblos y comunidades y proteger su integridad económica, social y cultural ${ }^{10}$.

En lo que atañe específicamente al desarrollo de los llamados 'proyectos económicos y de desarrollo' que se pretenda llevar a cabo en los territorios habitados por estos pueblos y que impliquen la extracción de recursos naturales, el Convenio 169 señala:

Artículo 15. 1. Los derechos de los pueblos interesados a los recursos naturales existentes en sus tierras deberán protegerse especialmente. Estos derechos com-

7 Véase Escobar, A. Conferencia: Conversaciones sobre el Sur global: Gobernanza, extractivismo y resistencia. Bogotá: Universidad del Rosario (24 de agosto de 2015). Disponible en: http://www.urosario.edu.co/Home/Principal/Eventos/Facultad-de-Jurisprudencia/ Conversaciones-sobre-el-Sur-Global/

8 El concepto de bloque de constitucionalidad hace referencia a aquellas normas y disposiciones que, si bien no hacen parte del texto constitucional, son consideradas parte integral de la Constitución, como es el caso de los tratados internacionales en materia de derechos humanos. $\mathrm{Al}$ respecto, la Corte Constitucional colombiana ha señalado explícitamente que los convenios emanados de la Organización Internacional del Trabajo hacen parte del derecho interno y que algunos de ellos forman parte en estricto sentido del bloque de constitucionalidad. Ver Corte Constitucional. Sentencias C-222 de 1995 y C-617 de 2008.

9 Artículos 6 y 7 del Convenio 169 de la ort.

10 Rodríguez, G. A. De la consulta previa, al consentimiento libre, previo e informado a pueblos indígenas en Colombia. Bogotá: Universidad del Rosario, GIz, Cooperación Alemana, 2014. 
prenden el derecho de esos pueblos a participar en la utilización, administración y conservación de dichos recursos.

2. En caso de que pertenezca al Estado la propiedad de los minerales o de los recursos del subsuelo, o tenga derechos sobre otros recursos existentes en las tierras, los gobiernos deberán establecer o mantener procedimientos con miras a consultar a los pueblos interesados, a fin de determinar si los intereses de esos pueblos serían perjudicados, y en qué medida, antes de emprender o autorizar cualquier programa de prospección o explotación de los recursos existentes en sus tierras. Los pueblos interesados deberán participar siempre que sea posible en los beneficios que reporten tales actividades, y percibir una indemnización equitativa por cualquier daño que puedan sufrir como resultado de esas actividades.

Por su parte, la Constitución Política de Colombia de 1991 incorporó explícitamente varias normas orientadas a proteger los derechos colectivos de los pueblos indígenas y de las comunidades afrodescendientes, como el derecho a la autodeterminación, el derecho al territorio y el derecho a la participación ${ }^{11}$.

Asimismo, la Corte Constitucional colombiana elevó la consulta previa a la categoría de 'derecho fundamental'. Al respecto, la Corte señaló que la explotación de los recursos naturales de los territorios indígenas ha de ser compatible con la protección que el Estado debe brindar a los pueblos y comunidades para garantizar su integridad económica, social y cultural. En palabras de la Corte, esta idea de integridad constituye un derecho fundamental de las comunidades debido a que está estrechamente relacionado con su supervivencia como grupo humano y como cultura. De esta manera, para asegurar la supervivencia de los grupos y comunidades étnicas es indis-

11 La Constitución Política de 1991 estableció varias normas sobre los derechos de los pueblos indígenas y las comunidades afrodescendientes, así como las obligaciones del Estado en relación con estos grupos. Algunas de las normas constitucionales que contienen estas disposiciones son las siguientes: la obligación del Estado de proteger el patrimonio cultural y natural de la nación (art. 8); la obligación del Estado de proteger la diversidad étnica y cultural y el derecho a la identidad cultural (arts. 1,7,70); el derecho a la igualdad y no discriminación de los pueblos indígenas y de las comunidades afrodescendientes (arts. 13 y 70); el derecho a la autodeterminación (arts. 9 y 330); el derecho al reconocimiento oficial de las lenguas de los pueblos indígenas y a impartir educación dentro de sus comunidades en sus lenguas nativas (art. 10); el derecho de los pueblos indígenas y de las comunidades afrodescendientes a ser consultados sobre las decisiones que pueden afectar sus derechos colectivos a través de procedimientos adecuados y contando con la participación efectiva de sus representantes en las instituciones (art. 68); el derecho a la igualdad y a la dignidad en todas las culturas (art. 70); la obligación del Estado de proteger el patrimonio arqueológico de la nación (art. 72); la obligación del Estado de asegurar la participación de los pueblos y comunidades étnicas en órganos democráticos representativos como el Senado y la Cámara de Representantes (arts. 171 y 176); el derecho de las autoridades indígenas a ejercer funciones judiciales dentro de su propia jurisdicción de acuerdo con sus propias normas y procedimientos (art. 246). 
pensable que se reconozca su derecho a la participación en decisiones que impliquen la explotación de recursos naturales en sus territorios ${ }^{12}$.

Dentro de las sentencias más destacadas de la Corte Constitucional colombiana en materia de consulta previa se encuentran las sentencias T-769 de 2009 y T-129 de 2011, donde se compilan varias decisiones relativas a casos de extracción de recursos en territorios indígenas, y se incluyen las siguientes decisiones: T-428 de 1992, SU-039 de 1997, T-652 de 1998, T-634 de 1999, SU-383 de 2003, T-955 de 2003, T-737 de 2005, T-880 de 2006, T-154 de 2009 y T-769 de $2009^{[13]}$.

Tanto en la sentencia T-769 de 2009 como en la T-129 de 2011, la Corte hizo referencia al alcance de la consulta previa como 'consentimiento' previo, libre e informado, particularmente en casos de proyectos económicos y de desarrollo que pretendieran llevarse a cabo en territorios habitados por grupos y comunidades étnicas y que además, pudieran causar serios impactos sociales, económicos y culturales sobre las comunidades y sus territorios.

Así, respecto a la discusión sobre si la consulta previa implica consentimiento o no, que es uno de los debates más controversiales en Colombia en materia de consulta previa, la Corte Constitucional señaló tres hipótesis en las cuales la consulta previa implica el consentimiento de las comunidades, y aclaró que en dichos escenarios debe agotarse primero el proceso de consulta y determinarse la imposibilidad de adoptar una medida alternativa o 'una medida menos perjudicial' para las comunidades frente a las acciones o proyectos que se pretenda realizar en sus territorios.

Los tres escenarios señalados por la Corte son los siguientes: primero, cuando un proyecto económico implique el traslado o desplazamiento de las comunidades; segundo, cuando un proyecto económico implique el almacenamiento o el vertimiento de desechos tóxicos en sus territorios; y tercero, cuando un proyecto pueda causar serios impactos sociales, culturales y ambientales sobre las comunidades al punto que se pueda poner en peligro su subsistencia.

La Corte argumentó que en las hipótesis señaladas la consulta previa implica consentimiento, si como consecuencia del proceso de consulta las comunidades llegan a la conclusión de que no es posible establecer alternativamente una 'medida menos perjudicial', y además, si se determina que en caso de llevar a cabo el proyecto en cuestión se podría causar la destrucción o la desaparición de los pueblos y comunidades que habitan el territorio donde se pretender realizar el proyecto. Según la Corte, en virtud del principio pro homine, los derechos de las comunidades deben prevalecer y por lo tanto

12 Corte Constitucional, Sentencia SU-039 de 1997.

13 Véase SuÁrez-RicaurTe, F. El derecho a la consulta previa de las comunidades indígenas, étnicas y tribales y la minería en Colombia. Una lectura a partir del derecho al territorio indígena. En Minería y desarrollo. Bogotá: Universidad Externado de Colombia, 2016. 
la decisión tomada por estas como resultado del proceso de consulta debe implicar el consentimiento en los escenarios referidos.

Cabe aclarar que esta decisión de la Corte coincide con lo dispuesto en la Declaración de las Naciones Unidas sobre los Derechos de los Pueblos Indígenas de 2007 y en la decisión de la Corte Interamericana de Derechos Humanos en el caso Saramaka v. Suriname ${ }^{14}$.

Por un lado, la Declaración establece que 'en general' es necesario buscar el consentimiento previo libre e informado antes de aprobar cualquier proyecto que pueda redundar en la afectación del territorio donde habitan las comunidades y de sus recursos. Por su parte, la decisión de la Corte Interamericana en el caso Saramaka v. Suriname tiene un alcance más limitado, pues establece que la consulta solo implica consentimiento en casos de proyectos de desarrollo o de inversión a gran escala que puedan causar un gran impacto en una buena parte del territorio donde habitan las comunidades ${ }^{15}$.

Al respecto, Suárez Ricaurte afirma que la decisión de la Corte en el caso Saramaka v. Suriname influyó sustancialmente en la posición de la Corte Constitucional colombiana sobre si la consulta previa implica o no consentimiento ${ }^{16}$. Igualmente, este autor explica que a partir de esta decisión y teniendo en cuenta la Declaración sobre los Derechos de los Pueblos Indígenas, la Corte Constitucional colombiana ha hecho una interpretación más amplia del Convenio 169 de la OIT $^{17}$.

Un ejemplo de ello es lo ocurrido en la sentencia T-769 de $2009^{[18]}$, donde la Corte señaló explícitamente la necesidad de obtener el consentimiento previo, libre e informado de los pueblos y comunidades étnicas en aquellos casos en que un proyecto pudiera acarrear un impacto de mayor alcance en los territorios de las comunidades, como ocurre en los casos de proyectos de desarrollo e inversión a gran escala.

14 Caso Saramaka v. Suriname, 2007 Corte Interamericana de Derechos Humanos. Disponible en: http://www.corteidh.or.cr/docs/casos/articulos/seriec_172_ing.pdf

15 Véase Merino, R. Coloniality and Indigenous Territorial Rights in the Peruvian Amazon: A Critique of the Prior Consultation Law (2015) 38 Bath Papers in International Development and Wellbeing Centre for Development Studies, University of Bath, disponible en: http://www. bath.ac.uk/cds/publications/bpd38.pdf

16 SuÁREZ-RICAURTE. El derecho a la consulta previa de las comunidades indígenas, étnicas y tribales y la minería en Colombia, cit.

17 Ibíd.

18 En la sentencia T-769 de 2009, la Corte Constitucional falló a favor de la comunidad Bachidubi del resguardo del río Murindó. En este caso, las autoridades nacionales habían emitido varios títulos mineros en favor de la compañía estadounidense Muriel Mining Corp. para la explotación de cobre, oro y molibdeno en las regiones de Antioquia y Chocó, en el marco del proyecto Mandé Norte. Una de la razones alegadas por la comunidad para rechazar el proyecto fue que con este se afectaba seriamente el cerro sagrado Careperro. Igualmente, la compañía no había consultado previamente a las comunidades antes del inicio de las actividades de exploración y de explotación en el cerro. 
Así, según la Corte Constitucional, el Estado colombiano tiene la obligación de llevar a cabo procesos de consulta previa con el propósito de obtener el consentimiento previo libre e informado de las comunidades, teniendo en cuenta sus tradiciones y costumbres. Esto se justifica porque como consecuencia de los proyectos de desarrollo o de inversión a gran escala se pueden causar serios impactos económicos, sociales, culturales y ambientales sobre las comunidades, como la pérdida de sus territorios, su expulsión, el agotamiento de recursos necesarios para su supervivencia física y/o cultural, la destrucción y polución del ambiente, entre otros ${ }^{19}$.

Por otro lado, en el caso que dio lugar a la sentencia T-129 de 2011, la Corte Constitucional colombiana falló a favor de la comunidad indígena Embera Katío de Pescadito, ubicada en la reserva indígena Chidima-Tolo. En esta sentencia, la Corte afirmó que en el marco de un proceso de consulta previa resulta insuficiente que las comunidades solo sean 'escuchadas' para efectos de dar cumplimiento al requisito de la consulta. Según la Corte, la opinión de las comunidades consultadas debe influenciar directamente la decisión sobre el proyecto de desarrollo que se quiere llevar a cabo en su territorio ${ }^{20}$.

De manera adicional, la Corte también aclaró que la consulta previa no solo debe llevarse a cabo en casos particulares, cuando se quiera realizar un proyecto específico de desarrollo o inversión, sino también cuando de manera general se tome cualquier decisión o se realice cualquier proyecto u obra de infraestructura que pueda afectar los territorios de las comunidades.

En este sentido, la Corte Constitucional hizo una interpretación más amplia de los artículos 6, 7 y 15 del Convenio 169 de la orT, explicando que el propósito de estas disposiciones es obtener efectivamente el consentimiento de los pueblos y comunidades indígenas a través del proceso de consulta previa ${ }^{21}$.

Por último, la Corte Constitucional también hizo referencia al artículo 32 de la Declaración de las Naciones Unidas sobre los Derechos de los Pueblos Indígenas ${ }^{22}$, y explicó que el nivel de impacto sobre las comunidades de los

19 Corte Constitucional, Sentencia T-769 de 2009.

20 SUÁREZ-RICAURTE. El derecho a la consulta previa de las comunidades indígenas, étnicas y tribales y la minería en Colombia, cit.

21 Ibíd.

22 Declaración de las Naciones Unidas sobre los Derechos de los Pueblos Indígenas. Resolución aprobada por la Asamblea General, 61/295, artículo 32: "1. Los pueblos indígenas tienen derecho a determinar y elaborar las prioridades y estrategias para el desarrollo o la utilización de sus tierras o territorios y otros recursos; 2. Los Estados celebrarán consultas y cooperarán de buena fe con los pueblos indígenas interesados por conducto de sus propias instituciones representativas a fin de obtener su consentimiento libre e informado antes de aprobar cualquier proyecto que afecte a sus tierras o territorios y otros recursos, particularmente en relación con el desarrollo, la utilización o la explotación de recursos minerales, hídricos o de otro tipo; 3 . Los Estados proveerán mecanismos eficaces para la reparación justa y equitativa por cualquiera de esas actividades, y se adoptarán medidas adecuadas para mitigar las consecuencias nocivas de orden ambiental, económico, social, cultural o espiritual". 
proyectos que se lleven a cabo debería incidir en la determinación de su nivel de participación.

\section{EL USO AMBIVALENTE DE LA CONSULTA PREVIA EN COLOMBIA: TRES CASOS EMBLEMÁTICOS}

Colombia es considerado como un país que cuenta con una gran diversidad en su riqueza naturale. Asimismo, desde la Constitución de 1991 ha sido reconocido como un país 'pluriétnico' y 'multicultural '23. Según la Organización Nacional de Indígena de Colombia (ONIC) ${ }^{24}$, se estima que actualmente viven 102 pueblos indígenas en territorio colombiano, de los cuales 18 se encuentran en peligro de extinción. Asimismo, según el Censo General del año 2005 realizado por el Departamento Administrativo Nacional (DANE), existen 1.378.884 indígenas en Colombia, de los cuales 933.800 viven en resguardos ${ }^{25}$. Por su parte, se estima que en Colombia existen 1.219 comunidades afrodescendientes que se encuentran ubicadas en 4.717.269 hectáreas del territorio nacional ${ }^{26}$.

En este contexto, la consulta previa representa uno de los pocos instrumentos del DIDHH con los que cuentan estos pueblos y comunidades para proteger sus territorios, frente al riesgo de ser despojados de los mismos por la realización de grandes proyectos económicos y de 'desarrollo', como lo son los proyectos a gran escala de extracción de recursos naturales.

Tal como se explicó en el acápite anterior de este artículo, según el artículo 6 del Convenio 169 de la ort, las autoridades nacionales deben consultar a las comunidades cuando cualquier medida de tipo administrativo o legislativo pueda afectarlas de manera directa ${ }^{27}$. Igualmente, las autoridades

23 Julieta Lemaitre explica que desde la Constitución Política de 1991 Colombia es entendida como una nación 'pluri-étnica' y 'multi-cultural', lo cual ha implicado el reconocimiento de los pueblos indígenas como 'sujetos de derecho'. Según Lemaitre, la comprensión de los derechos de los pueblos indígenas desde una perspectiva 'multicultural' implica, por un lado, reconocer la 'diferencia' de dichos pueblos, asimilándolos como una 'cultura diferente'; en segundo término, implica entender esa diferencia como algo positivo; y en tercer lugar, significa asegurar su autonomía y autodeterminación como pueblos. En este sentido, el multiculturalismo demanda la existencia y la aceptación de los 'otros' y de una cultura 'diferente'. Por ello, Lemaitre explica que la diferencia entre los pueblos indígenas y la 'mayoría' de los integrantes de la nación, compuesta por una población mestiza, es la base del reconocimiento de los derechos de los pueblos indígenas. Véase Lemaitre Ripoll. El derecho como conjuro, cit., 297-299.

24 Cmsonicorgco, Organización Nacional Indígena de Colombia - ONIC, 2015, disponible en: http://cms.onic.org.co/

25 Acnurorg, Pueblos Indígenas en Colombia - Pueblos Indígenas, 2015, disponible en: http://www.acnur.org/t3/pueblos-indigenas/pueblos-indigenas-en-colombia/

26 Departamento Administrativo Nacional de Estadística DANE, Colombia, una nación multicultural. Su diversidad étnica. Bogotá: DANE, 2007, 23-24, disponible en: http://www.dane. gov.co/files/censo2005/etnia/sys/colombia_nacion.pdf

27 Convenio 169 de la OIT, artículo 6: "1. Al aplicar las disposiciones del presente 
deben establecer los medios para que las comunidades puedan participar libremente en la toma de decisiones en organismos de tipo administrativo y en otras entidades responsables de diseñar y ejecutar las políticas públicas y programas que impliquen su afectación.

Por su parte, el Convenio 169 de la orT también señala que las consultas que se realicen a las comunidades en el marco de esta norma, deben llevarse a cabo de buena fe, teniendo en cuenta el propósito de buscar un acuerdo o consentimiento sobre las medidas que se están proponiendo.

Sin embargo, a pesar de lo establecido por dicha norma, la consulta previa ha sido utilizada en algunos casos para propósitos diferentes a los señalados en la Convención, poniendo en entredicho su carácter emancipatorio así como su efectividad para proteger los territorios de los pueblos y comunidades étnicas en Colombia.

En efecto, de manera 'paradójica', la consulta también se ha empleado como una herramienta en detrimento de la protección de los territorios de los pueblos y comunidades, causando la división al interior de estos grupos, así como su cooptación por grandes actores económicos que han sido clave en el desarrollo de proyectos extractivos enmarcados en la dinámica propia de un sistema de gobernanza global. Esto ha sido posible debido en parte a las precarias condiciones sociales y económicas en que suelen vivir las comunidades y pueblos étnicos en Colombia, lo cual hace a estos grupos más vulnerables para aceptar pagos o acuerdos a cambio de su consentimiento para la realización de proyectos económicos a gran escala en sus territorios.

Bajo esta dinámica, tal como ocurrió en el caso del Parque Nacional Natural Yaigojé-Apaporis, en algunos casos grandes compañías mineras han promovido y patrocinado por distintos medios procesos de consulta previa con el propósito de evitar que ciertos territorios sean declarados como parques o como reservas naturales, debido a que en Colombia está prohibido llevar a cabo actividades extractivas, como actividades de minería a gran escala, en este tipo de territorios.

Por su parte, de acuerdo a lo señalado en líneas anteriores, uno de los principales debates que han surgido en la doctrina sobre la consulta previa

Convenio, los gobiernos deberán: a) consultar a los pueblos interesados, mediante procedimientos apropiados y en particular a través de sus instituciones representativas, cada vez que se prevean medidas legislativas o administrativas susceptibles de afectarles directamente; b) establecer los medios a través de los cuales los pueblos interesados puedan participar libremente, por lo menos en la misma medida que otros sectores de la población, y a todos los niveles en la adopción de decisiones en instituciones electivas y organismos administrativos y de otra índole responsables de políticas y programas que les conciernan; c) establecer los medios para el pleno desarrollo de las instituciones e iniciativas de esos pueblos, y en los casos apropiados proporcionar los recursos necesarios para este fin. 2 . Las consultas llevadas a cabo en aplicación de este Convenio deberán efectuarse de buena fe y de una manera apropiada a las circunstancias, con la finalidad de llegar a un acuerdo o lograr el consentimiento acerca de las medidas propuestas". 
es el relativo a si la consulta implica o no el 'consentimiento' de las comunidades y pueblos consultados, y si el resultado del proceso de consulta es o no es vinculante. Dentro de esta discusión, la posición de que la consulta no debe ser vinculante ha resultado especialmente problemática porque en la práctica grandes compañías se han valido de esta para terminar asimilando la consulta previa simplemente, por un lado, a un requisito de procedimiento que deben agotar para poder llevar a cabo sus proyectos, y por otro lado, a un instrumento que puede resultar útil para legitimar y legalizar tanto sus proyectos como las consecuencias derivadas de estos tanto en términos ambientales como sociales.

Así, a pesar del propósito de la consulta previa señalado en el Convenio 169 de la ort de garantizar la participación de los pueblos y comunidades étnicas en la toma de decisiones en general y en proyectos particulares que puedan afectar sus territorios, y a pesar de la amplia interpretación que ha hecho la Corte Constitucional colombiana sobre los alcances de la consulta como consentimiento, la consulta ha sido utilizada en algunos casos de forma ambivalente, causando efectos contrarios a los pretendidos por la norma.

También es importante resaltar que el problema descrito sobre los usos ambivalentes de la consulta previa y algunos de los principales debates actuales que giran en torno a la consulta previa (tales como si la consulta implica consentimiento o no, si la decisión tomada en el marco del proceso de la consulta es vinculante o no, si es un instrumento que en la práctica ha sido utilizado para propósitos diferentes a los de proteger los territorios de los pueblos y comunidades étnicas) tienen una estrecha relación con el contexto global y (neo)colonial en el que se enmarca este problema.

En efecto, la problemática descrita y los debates que se derivan de ella están estrechamente relacionados con fenómenos que trascienden las fronteras de los países (p. ej., el auge de industrias como la industria extractiva y la oscilación a nivel mundial del precio de los commodities), los cuales tienen una incidencia directa tanto en el comportamiento de las grandes compañías que realizan proyectos económicos a gran escala como en el comportamiento de los gobiernos y en su posición frente a instituciones que pueden interferir en la realización de dichos proyectos, como ocurre con la consulta previa. Al respecto, Roger Merino afirma también que actores clave en la realización de este tipo de proyectos, como lo son las instituciones financieras internacionales, promueven este tipo de proyectos reconociendo en una menor medida y restringiendo de manera casi exclusiva el derecho de los pueblos y comunidades étnicas a la participación económica y social en dichos proyectos ${ }^{28}$.

Merino. Coloniality and Indigenous Territorial Rights in the Peruvian Amazon, cit., 8. 
Desde la perspectiva del pensamiento colonial, que es la mirada a partir de la cual se analizará este problema en las secciones subsiguientes, la problemática en torno al uso ambivalente de la consulta cuestiona que el uso que se les da a los territorios de los pueblos y comunidades étnicas, así como las instituciones que dentro de una lógica liberal han sido creadas para proteger los territorios de esos grupos, terminan respondiendo a estándares de eficiencia de la lógica liberal que es consecuente con la racionalidad económica dominante. De acuerdo a esta lógica, tanto el Estado como otros actores pueden, en nombre del interés general, disponer de los territorios de dichos grupos, quienes, también como consecuencia de dicha lógica, podrían ser compensados 'económicamente' en caso de probar que les ha sido causado un daño como consecuencia de las acciones de los otros actores.

Esto demuestra que las limitaciones de la consulta previa y las restricciones que esta conlleva, responden principalmente a una visión occidental que se ve reflejada en los usos 'eficientes' que se le dan al territorio en el que se encuentran asentados los pueblos y comunidades étnicas; en las formas y medios a través de los cuales estos son compensados 'económicamente' en caso de demostrar que se les ha causado un daño; así como en la forma en que estos grupos son percibidos y en las restricciones que implica dicha visión para el 'reconocimiento' de su 'plena' existencia ${ }^{29}$.

Al respecto, Merino explica que bajo la lógica del pensamiento liberal, que es el pensamiento dominante, los pueblos indígenas deben ser integrados, incluidos, asimilados y acomodados al marco liberal de las minorías étnicas, de tal manera que estas 'minorías' pueden 'participar' de los beneficios del 'desarrollo'. Sin embargo, este pensamiento también devela la imposibilidad de entender bajo la mirada occidental a estos grupos como naciones con un propio modelo de desarrollo y con los mismos derechos sobre el territorio que reclaman otros sujetos como las corporaciones y el Estado ${ }^{30}$.

Dicho lo anterior, a continuación se presentan tres casos que ilustran el uso ambivalente que se le ha dado a la consulta previa en Colombia. En los tres casos se promovieron diferentes proyectos económicos de gran escala que implicaban serios impactos sociales y ambientales para los pueblos y comunidades que habitaban los territorios en donde se pretendían realizar tales proyectos, y en los tres casos la utilización de la consulta previa acarreó dificultades de diversa índole que desafiaron los propósitos de esta institución de acuerdo al Convenio 169 de la OIT, a la vez que cuestionaron su carácter emancipatorio y su efectividad para proteger a los pueblos y comunidades que pudieran resultar afectados con la consulta.

29 Sobre este punto es importante resaltar que en el marco de las discusiones preliminares del Convenio 169 de la orт tanto el Estado como el sector privado decidieron incluir el concepto de 'participación', a la vez que descartaron los conceptos de 'control' y de 'autodeterminación'.

30 Merino. Coloniality and Indigenous Territorial Rights in the Peruvian Amazon, cit., 8. 
2.1. EL CASO DE LA DECLARATORIA DEL PARQUE NACIONAL NATURAL YAIGOJÉ-APAPORIS: ¿QUIÉNES PATROCINAN LA CONSULTA PREVIA Y CON QUÉ PROPÓSITO?

El primer ejemplo ilustrativo sobre la ambivalencia del uso de la consulta previa en Colombia está relacionado con la disputa del Parque Nacional Natural Yaigojé-Apaporis en la región de la Amazonía colombiana. Algunos de los miembros de las comunidades indígenas (makuna, tanimuka, tuyuca, cabiyari, letuama, yauna, yujup-maku) asentadas en esta región presentaron una acción de tutela ${ }^{31}$ en contra del Ministerio del Medio Ambiente y Desarrollo Sostenible de Colombia, la Asociación de Capitanes Indígenas del Resguardo Yaigojé Apaporis (ACIYA) y Parques Nacionales Naturales de Colombia que es la institución pública a cargo del manejo y protección de los parques nacionales y reservas naturales en Colombia.

Las comunidades indígenas representadas en la Asociación de Capitanes Indígenas de Taraira-Vaupés (Activata) alegaron que las entidades demandadas habían violado su derecho fundamental a la consulta previa respecto de la declaratoria del parque natural ${ }^{32}$. En efecto, en el año 2009 Parques Nacionales Naturales de Colombia declaró el área en disputa como Parque Nacional Natural Yaigojé-Apaporis, esto con el apoyo de la Asociación de Capitanes Indígenas del Resguardo Yaigojé Apaporis (ACIYA) ${ }^{33}$.

Activata, asociación demandante en el proceso y que agrupa a varias comunidades afectadas con las declaración del parque, argumentó que como consecuencia de la declaratoria del territorio de las comunidades como parque natural, estas tenían prohibido acceder a los recursos de fauna y flora del área demarcada, afectándose con ello el acceso a medios necesarios para su subsistencia.

De conformidad con la jurisprudencia de la Corte Constitucional colombiana atrás referida, en principio la decisión que debía tomar este tribunal sobre la acción de tutela interpuesta por las comunidades demandantes era

31 Sobre la importancia de la acción de tutela y su incorporación en el ordenamiento jurídico colombiano a partir de la Constitución de 1991 véase EsLAVA, L. Constitutionalization of Rights in Colombia: Establishing a ground for meaningful comparisons. Revista Derecho del Estado, 2009 , n. ${ }^{\circ}$ 22, 204, disponible en: http://revistas .uexternado.edu.co/index.php/derest

32 Medio Ambiente, Redacción. Minera Cosigo no pudo tumbar el Parque Apaporis. El Espectador, 2015, disponible en: http://www.elespectador.com/noticias/medio-ambiente/ minera-cosigo-no-pudo-tumbar-el-parque-apaporis-articulo-583189; La Silla Vacía , La minera que quería tumbar el parque amazónico, 2014, disponible en: http://lasillavacia.com/historia/ la-minera-que-estaba-detras-de-la-tutela-al-parque-amazonico-46563; Silva-Herrera, J. Tres magistrados van a la selva; evalúan si permiten extracción de oro. El Tiempo, 2014, disponible en: http://www.eltiempo.com/archivo/documento/CMs-13427338.

33 Velásquez-Ruiz, M. Al que no quiere caldo: Tobie Mining Inc. demanda a Colombia por 16.5 billones de dólares, 2016, disponible en: Desmarcado http://blogs.eltiempo.com/desmarcado/2016/03/22/tobie-mining-demanda-colombia/ 
más o menos predecible, debido a que, de acuerdo al Convenio 169 de la OIT, el Estado está obligado a consultar a las comunidades antes de adoptar cualquier disposición legislativa o administrativa con la que las comunidades puedan resultar afectadas, como ocurre precisamente con la declaración de una zona como parque natural cuando pueda acarrear la restricción al acceso de los grupos indígenas a la zona demarcada.

Asimismo, dada la importancia que la zona objeto de disputa representa en términos ambientales para el país, había una expectativa de la sociedad en general frente a la decisión que iba a tomar la Corte Constitucional respecto de la declaratoria del área como parque natural por parte de Parques Nacionales Naturales de Colombia sin haber llevado a cabo la consulta previa.

Sin embargo, un hecho inesperado cambió la que parecía iba a ser la decisión de la Corte. Con ocasión de una audiencia a la que asistieron varios magistrados de la Corte Constitucional y que tuvo lugar en la Amazonía colombiana, en cercanías del área demarcada, Benigno Perrilla, líder indígena de la Asociación de Capitanes Indígenas de Taraira-Vaupés ${ }^{34}$, confesó que la acción de tutela en contra de Parques Nacionales Naturales de Colombia alegando la violación al derecho fundamental a la consulta previa había sido promovida por la compañía canadiense Cosigo Resources, como parte de una estrategia para proteger los títulos mineros adquiridos por ella dentro del área declarada como parque ${ }^{35}$.

En efecto, Cosigo Resources había logrado que el Estado colombiano le otorgara algunos títulos mineros dentro del área que había sido reconocida como parque natural, títulos que le permitían realizar operaciones por un periodo de 29 años. Sin embargo, cabe aclarar que también había una discusión sobre la validez de los títulos adquiridos por la compañía, debido a que estos fueron expedidos dos días después de que Parques Nacionales Naturales de Colombia declarara el Parque Nacional Natural Yaigojé-Apaporis ${ }^{36}$.

Es así como Cosigo Resources pretendía remover la decisión por medio de la cual se había declarado el área en disputa como parque natural. Valiéndose del derecho de las comunidades a la consulta previa. En efecto, solo en la medida en que dicha decisión fuera derogada, la compañía canadiense podría hacer uso de sus títulos mineros para explorar y explotar el territorio

34 La asociación Activata es el resultado de una serie de acciones realizadas por las compañías mineras con las que se logró dividir a las comunidades ubicadas en el área demarcada por el Parque Yaigojé-Apaporis. De hecho, las compañías involucradas en este caso prometieron a los miembros de esta asociación otorgarles el 20\% de los beneficios derivados de la concesión minera.

35 Bermúdez-Liévano, A. La minera que quería tumbar el parque amazónico. La Silla Vacía , 2014, disponible en: http://lasillavacia.com/historia/la-minera-que-estaba-detras-de-latutela-al-parque-amazonico-46563

36 Velásquez-Ruiz, $\mathrm{Al}$ que no quiere caldo, cit. 
en disputa, ya que las actividades de minería son prohibidas por la ley colombiana en las zonas declaradas como parques naturales.

Posteriormente y como consecuencia de lo ocurrido en la audiencia referida, la Corte Constitucional emitió la sentencia T-384A de 2014 negando la petición de los demandantes en la acción de tutela. La Corte confirmó la decisión de Parques Nacionales Naturales de Colombia de declarar el Parque Nacional Natural Yaigojé-Apaporis, y ordenó suspender inmediatamente las actividades de exploración y explotación llevadas a cabo por la compañía canadiense. De manera adicional, la Corte ordenó a las autoridades no expedir ningún título minero sobre el área declarada como parque natura ${ }^{37}$.

Sin embargo, después de la sentencia emitida por la Corte y como consecuencia de la misma, en febrero de 2016 Cosigo Resources y la estadounidense Tobie Mining and Energy Inc. demandaron al Estado colombiano ante un tribunal de arbitramento de inversión ${ }^{38}$, en el marco del Tratado de Libre Comercio Colombia-Estados Unidos, el cual había entrado en vigencia en el año 2012. Al respecto cabe resaltar que la compañía estadounidense había comprado en mayo de 2015 algunas acciones a la Cosigo Resources.

Ambas compañías señalaron que el Estado colombiano debía pagarles una suma que ascendía a los 16.5 billones de dólares, equivalente al 12\% del presupuesto anual del Estado colombiano, en compensación por el valor de los recursos dejados de explotar después de que Corte Constitucional negara la acción de tutela que alegaba la violación al derecho a la consulta previa, promovida, como se dijo, por la compañía canadiense ${ }^{39}$. Actualmente, el caso no ha sido resuelto por el tribunal de arbitramento.

\subsection{EL PROYECTO MANDÉ NORTE EN EL CERRO KATUMA JAIDE: ¿QUIÉN ESTÁ LEGITIMADO PARA REALIZAR LA CONSULTA PREVIA?}

Un segundo caso que resulta ilustrativo del uso ambivalente de la consulta previa en Colombia es el relacionado con el proyecto de oro a gran escala en Colombia conocido como Mandé Norte, en el monte sagrado Katuma Jaide ${ }^{40}$. Este caso se refiere a un conflicto entre la compañía estadounidense Muriel Mining Corp. y varios pueblos y comunidades indígenas y afrodescendientes

37 Corte Constitucional. Sentencia T-384A de 2014, disponible en: http://www.corteconstitucional.gov.co/relatoria/2014/t-384a-14.htm

38 Véase Cosigo Resources Ltd., Cosigo Resources Sucursal Colombia and Tobie Mining and Energy, Inc. (Investors) v. The Republic of Colombia (Respondent), disponible en: http:// www.italaw.com/sites/default/files/case-documents/italaw7172.pdf

39 Velásquez-Ruiz, Al que no quiere caldo, cit.

40 Corte Constitucional. Sentencia T-769 de 2009, disponible en: http://www.corteconstitucional.gov.co/relatoria/2009/t-769-09.htm; Peace Brigades International, PBI Project Colombia, Proyecto Mandé Norte sigue en pie, 2011, disponible en: http://www.pbi-colombia.org/fieldprojects/pbi-colombia/news-from-colombia/news/?tx_ttnews\%5Btt_news $\% 5 \mathrm{D}=2628 \& \mathrm{cHash}=$ bf399b6882f8dc82bde42ddb9808dbde 
asentados en el Departamento del Chocó ${ }^{41}$. Cabe resaltar que en este Departamento existen 115 resguardos indígenas donde se encuentran los pueblos Embera, Embera Chamí, Embera Katio, Tule y Waunan ${ }^{42}$.

La comunidad indígena Embera Dobida, del resguardo Uradá Jiguamiandó. Vive en un área en la que Muriel Mining Corp. pretendía desarrollar un proyecto de minería de oro a gran escala. El área disputada se encuentra localizada en la región del Bajo Atrato, en el Municipio de Carmen del Darién. En el año 2003, las autoridades colombianas reconocieron que los indígenas que habitaban el área demarcada, equivalente a 20.000 hectáreas, estaban asentados allí desde antes de la Conquista española. Dicho resguardo está ubicado en la zona del Alto Guayabal, Uradá y Nuevo Cañaveral. El proyecto de la compañía implicaba impactos en las comunidades afrodescendientes de Jiguamiandó.

En el año 2005, Muriel Mining Corp. inició un proyecto de minería de oro a gran escala sobre 16.000 hectáreas, en el marco de un contrato de concesión firmado entre esta compañía y el Estado colombiano que le permitiría a aquella realizar operaciones en el área demarcada, por un periodo de 30 años prorrogable por 30 años más ${ }^{43}$. El proyecto minero pretendía desarrollarse en un área en la que estaba ubicado un cerro sagrado para las comunidades que habitan ese territorio, siendo este uno de los aspectos más controversiales, junto con los graves impactos ambientales que podría suponer su desarrollo, así como sus efectos sobre la subsistencia de los grupos y comunidades asentados allí, en especial teniendo en cuenta que se vería restringido para estos el acceso a recursos de flora y fauna indispensables para su supervivencia ${ }^{44}$.

En desarrollo del proyecto minero de Mandé Norte ocurrió un hecho de particular gravedad. Durante la realización del mismo se ordenó la militari-

41 El Departamento del Chocó es una de las regiones de Colombia donde habita el mayor porcentaje de población afrodescendiente. Según el Departamento Administrativo Nacional De Estadística (DANE), en el Chocó, el 82.12\% de la población es afrocolombiana, mientras que en otras regiones como San Andrés y Providencia el porcentaje equivale al $56.98 \%$, del cual el $69.09 \%$ corresponde a la población nativa de la isla. Por su parte, en Bolívar se estima que el $27.61 \%$ de la población es afrocolombiana, en Valle del Cauca el 27.20\% y en el Departamento del Cauca el 22.20\%. Asimismo, el DANE afirma que alrededor del $57.28 \%$ del total de la población afrocolombiana está ubicada en las regiones de Valle del Cauca, Antioquia, Bolívar y Chocó, mientras que el $17.48 \%$ vive en Nariño, Cauca y Atlántico. Véase Departamento Administrativo Nacional de Estadística-DANE, Colombia, una nación multicultural. Su diversidad étnica. Bogotá: DANE, 2007, 21-39, disponible en: http://www.dane.gov.co/files/censo2005/etnia/sys/ colombia_nacion.pdf

42 Ibíd., 21.

43 Corte Constitucional. Sentencia T-769 de 2009, disponible en: http://www.corteconstitucional.gov.co/relatoria/2009/t-769-09.htm

44 Peace Brigades International, PBI Project Colombia, Proyecto Mandé Norte sigue en pie, 2011, disponible en: http://www.pbi-colombia.org/field-projects/pbi-colombia/news-fromcolombia/news/?tx_ttnews\%5Btt_news\%5D=2628\&cHash=bf399b6882f8dc82bde42ddb9808 dbde 
zación del área en disputa con el objeto de proteger los títulos mineros sobre el territorio que le habían sido concedidos a la compañía ${ }^{45}$. Las acciones de militarización incluyeron ataques aéreos, y como resultado de dichas acciones miembros de las comunidades indígenas sufrieron graves heridas ${ }^{46}$. Ante la gravedad de lo ocurrido, la Comisión Interamericana de Derechos Humanos solicitó al Estado colombiano la adopción de medidas cautelares ${ }^{47}$ para prevenir que se causaran daños irreparables a las comunidades como consecuencia de la violación de sus derechos ${ }^{48}$.

45 Ibíd.

46 Misión Humanitaria de Verificación (Organización Indígena de Antioquia - OIA; Oficina del Alto Comisionado de las Naciones Unidas para los Refugiados - ACNUR; Oficina de Derechos Humanos de la Organización de las Naciones Unidas - onU; Defensoría del Pueblo Regional Urabá; la Organización No Gubernamental Brigadas de Paz - PBI; Organización No Gubernamental Justicia y Paz; Organización Nacional Indígena de Colombia - ONIC; Guardia Indígena del Resguardo de Polines y Chigorodó). Informe Misión Humanitaria de Verificación Comunidad Indígena Embera Katio de Alto Guayabal-Urada Jiguamiandó (Carmen del Darién, Antioquia-Chocó, 2010), disponible en: www.onic.org.co/img_upload/3068e9df14b050d72c4f a19fabbab2d7/INFORME_URADA.doc

47 Según la Comisión Interamericana de Derechos Humanos, "the mechanism for precautionary measures is established in Article 25 of the rules of procedure of the IACHR. The Rules of Procedure establish that, in serious and urgent situations, the Commission may, on its own initiative or at the request of a party, request that a State adopt precautionary measures to prevent irreparable harm to persons or to the subject matter of the proceedings in connection with a pending petition or case, as well as to persons under the jurisdiction of the State concerned, independently of any pending petition or case. The measures may be of a collective nature to prevent irreparable harm to persons due to their association with an organization, a group, or a community with identified or identifiable members. As a result, the number of precautionary measures granted does not reflect the number of persons protected by their adoption; as can be seen below, many of the precautionary measures issued by the IACHR protect more than one person and, in certain cases, groups of persons such as communities or indigenous peoples. Moreover, the Rules of Procedure establish that the granting of such measures and their adoption by the State shall not constitute a prejudgment on the violation of the rights protected by the American Convention on Human Rights or other applicable instruments. On August 1, 2013 the amended Rules of Procedure entered into force and established that 'the decisions granting, extending, modifying or lifting precautionary measures shall be adopted through reasoned resolutions"'. Oasorg. OAS: IACHR: Precautionary Measures, 2015, disponible en: http://www.oas.org/en/iachr/decisions/precautionary.asp.

48 Medidas cautelares en favor de la Comunidad del Alto Guayabal-Coredocito del Pueblo Emberá, Colombia, [2010] MC 12-09 (Inter-American Commission of Human Rights). Disponible en: http://www.oas.org/es/cidh/decisiones/cautelares.asp "El 25 de febrero de 2010, la cIDH otorgó medidas cautelares a favor de 87 familias de la Comunidad Alto Guayabal-Coredocito, del Pueblo Emberá, declarada "So Bia Drua" (área humanitaria) del Resguardo Indígena Uradá Jiguamiandó, Municipio de Carmen del Darién, Departamento de Chocó. En la solicitud de medida cautelar se alega que esta comunidad habría sido objeto de actos de violencia que pusieron en riesgo la vidas e integridad personal de sus integrantes. Se alega, entre otros hechos, que el 30 de enero de 2010 dos helicópteros y un avión de las fuerzas armadas habrían realizado un ametrallamiento y bombardeo a 300 metros del asentamiento principal de la comunidad, impactando la casa de una familia donde se encontraban tres adultos y dos niños, que resultaron heridos. Se indica, por ejemplo, que el señor José Nerito Rubiano Bariquí fue herido en el tórax con arma de fuego, a raíz de lo cual sufrió ruptura de columna vertebral y quedó parapléjico. Según los solicitantes de la medida, la presencia militar en la zona estaría relacionada con la reanudación de la explo- 
De manera paralela, algunas de las comunidades afectadas interpusieron una acción de tutela, argumentando que la compañía había iniciado en su territorio acciones de exploración sin que estas hubieran sido consultadas previamente. En el año 2009, la Corte Constitucional falló a favor de las comunidades y ordenó la suspensión del proyecto minero hasta tanto estas no fueras consultadas en debida forma ${ }^{49}$.

A pesar de la decisión de la Corte a favor de las comunidades indígenas, la compañía y el Ministerio del Interior y de Justicia presentaron una acción legal con el objeto de que la decisión de la Corte fuera declarada nula. Sin embargo, en el Auto 053 de 2012, la Corte negó la solicitud de nulidad.

Asimismo, como consecuencia de la decisión de la Corte algunas comunidades adelantaron el proceso de consulta previa y decidieron que el proyecto minero de la compañía no podía llevarse a cabo en su territorio, ya que con dicho proyecto las comunidades podrían verse seriamente afectadas y se podría cambiar drásticamente su forma de vida. Sin embargo, las autoridades nacionales no aceptaron el resultado ni la 'legalidad' de esa consulta, alegando que la única institución autorizada para llevar a cabo un proceso de consulta previa en Colombia era el Ministerio del Interior.

Por otro lado, después de la sentencia emitida por la Corte Constitucional surgieron nuevos conflictos en torno al territorio en disputa. En efecto, según algunos miembros del equipo que brinda apoyo jurídico a las comunidades, debido a las difíciles condiciones sociales y económicas en las que estas se encuentran, la compañía ha logrado persuadir a algunos de sus miembros de la conveniencia del proyecto minero, con el objetivo de cooptarlos y dar inicio a un nuevo proceso de consulta, esta vez avalado por las autoridades nacionales. Por ello, las comunidades se encuentran actualmente divididas y las autoridades aún no han podido realizar un nuevo proceso de consulta que cuente con la participación de todas las comunidades que pueden resultar afectadas.

\subsection{EL CASO DE LA REPRESA DE URRÁ EN EL RÍO SINÚ:}

¿CUÁLES SON LAS IMPLICACIONES PARA LOS PUEBLOS INDÍGENAS, ANTES Y DESPUÉS DE REALIZAR EL PROCESO DE CONSULTA PREVIA?

Un tercer ejemplo de la ambivalencia de la consulta previa en Colombia es el famoso caso de la construcción de la represa de Urrá ${ }^{50}$. Debido a su com-

tación minera. La Comisión Interamericana solicitó al Estado de Colombia adoptar las medidas necesarias a fin de proteger la vida e integridad personal de 87 familias de la Comunidad Alto Guayabal-Coredocito; concertar las medidas a adoptarse con los beneficiarios y sus representantes; e informar sobre las acciones de investigación adoptadas respecto de los hechos que dieron lugar a la adopción de medidas cautelares a fin de remover los factores de riesgo para los beneficiarios.

49 Corte Constitucional. Sentencia T-769 de 2009, disponible en: http://www.corteconstitucional.gov.co/relatoria/2009/t-769-09.htm

50 Comisión Colombiana de Juristas. "Urrá II", una amenaza mortal para el pueblo indí- 
plejidad y a los serios impactos que se causaron con este proyecto, tanto en términos sociales como ambientales, este caso es reconocido como uno de los más controversiales en la construcción de proyectos a gran escala que se han llevado a cabo en territorios indígenas.

A inicios de los años noventa, el proyecto conocido como "Urrá I" fue construido en el territorio donde estaba asentada la comunidad indígena Embera Katío. Como consecuencia de la construcción de la represa fueron violados algunos de los derechos de los miembros de dicha comunidad, tales como el derecho a la propiedad, el derecho al control y acceso de alimentos, el derecho a la salud, el derecho a una vivienda digna, el derecho a la cultura, el derecho a la libertad religiosa, entre otros ${ }^{51}$. De manera adicional. Varios miembros de las comunidades allí asentadas fueron obligados a desplazarse de su territorio y a reasentarse, debido a los graves impactos causados con la construcción de la represa. Igualmente, los indígenas vieron cómo miembros de su comunidad se vieron obligados a cambiar sus tradiciones, así como sus formas de vida y sus medios de subsistencia ${ }^{52}$.

En el año 1993, el Instituto Nacional de los Recursos Naturales Renovables y del Ambiente (Inderena) permitió la construcción de la represa sin que se llevara a cabo la consulta previa de acuerdo a la Covenio 169 de la OIT $^{53}$. Sin embargo, con posterioridad fueron requeridas algunas autorizaciones y licencias para poder dar continuidad al proyecto de la represa de Urrá, incluyendo el requisito de la consulta previa. Así, en 1997 el Ministerio de Ambiente negó el otorgamiento de una licencia que se requería para las nuevas etapas del proyecto alegando el no cumplimiento de varios de los requisitos establecidos por la ley ${ }^{54}$.

Posteriormente, en 1998 la Corte Constitucional emitió una sentencia en favor de la comunidad Embera Katío y ordenó suspender algunas de las acciones requeridas para continuar con el proyecto de la construcción de la represa, hasta tanto no se llevara a cabo el proceso de consulta previa. La Corte también ordenó pagar una suma individual por concepto de compensación monetaria a la comunidad Embera Katío por los daños causados con la construcción de la represa ${ }^{55}$.

Luego de la decisión de la Corte Constitucional surgieron nuevos conflictos. Uno de ellos fue el de las amenazas de grupos paramilitares que acusaron a miembros de la comunidad indígena de tener nexos con grupos armados

gena Embera Katío del alto Sinú, 2008, disponible en: http://www.coljuristas.org/documentos/ boletines/bol_n22_975.pdf

51 Ibíd.

52 Ibíd.

53 Ibíd.

54 Ibíd.

55 Corte Constitucional. Sentencia T-652 de 1998, disponible en: http://www.corteconstitucional.gov.co/relatoria/1998/T-652-98.htm 
ilegales como los grupos guerrilleros ${ }^{56}$. De otra parte, en octubre de 1999 el Ministerio de Ambiente otorgó una licencia ambiental para que se pudiera realizar la construcción de la represa, desconociendo la sentencia emitida por la Corte Constitucional ${ }^{57}$.

En el marco de los conflictos que se generaron en el territorio como consecuencia de la construcción de la represa de Urrá, al menos 9 miembros de la comunidad Emberá Katío fueron asesinados o desaparecidos, presuntamente por grupos paramilitares ${ }^{58}$. Algunas organizaciones no gubernamentales de derechos humanos, como la Comisión Colombiana de Juristas, señalaron que las decisiones emitidas por la Corte no habían sido implementadas adecuadamente y que el Estado colombiano no había podido establecer la verdad sobre los crímenes cometidos en contra de la comunidad Embera Katío ${ }^{59}$.

Posteriormente y a pesar de las serias consecuencias causadas por la construcción de la represa de Urrá, se inició la construcción de una segunda fase del proyecto que se llamó "Urrá II" 60 . De manera similar a lo ocurrido en la fase I del proyecto, durante el desarrollo de la fase ir y como consecuencia de la sentencia emitida por la Corte Constitucional, emergieron nuevos conflictos entre los miembros de la comunidad.

Por ejemplo, una de las medidas ordenadas por la Corte fue la de compensar económicamente a la comunidad por los daños causados con la construcción de la represa. Dado que la represa ya había sido construida durante el desarrollo de la fase i del proyecto, y por esa razón no era posible que la Corte ordenara la suspensión del proyecto hasta que no se realizara el proceso de consulta, las medidas emitidas por la Corte se vieron limitadas a ordenar la compensación económica individual de los miembros de los pueblos indígenas.

Sobre este punto, la organización Dejusticia señaló que los impactos causados a los Embera Katío y las divisiones que se produjeron entre los miembros de esta comunidad no fueron consecuencia de los daños causados con la construcción de la represa, sino de la fórmula que la Corte Constitucional adoptó para compensar a la comunidad ${ }^{61}$. En efecto, una de la órdenes emitidas por la Corte en la sentencia T-652 de 1998 estableció que la compañía que adelantó la construcción de la represa de Urrá debía pagar a la comunidad ciertas sumas de dinero por concepto de compensaciones individuales durante un periodo de 20 años. Según Dejusticia, infortunada-

56 Comisión Colombiana de Juristas. "Urrá II", cit.

57 Ibíd.

58 Ibíd.

59 Ibíd.

60 Ibíd.

61 Orduz-Salinas, N. y Rodríguez-Garavito, C. Adiós río. La disputa por la tierra, el agua y los derechos indígenas en torno a la represa de Urrá, 2012, disponible en: https:// justiciaambientalcolombia.org/2012/09/27/nuevo-libro-de-dejusticia\%E2\%80\%8B-adios-riola-disputa-por-la-tierra-el-agua-y-los-derechos-indigenas-en-torno-a-la-represa-de-urra/ 
mente la Corte no previó las consecuencias adversas que traería el pago de las compensaciones monetarias individuales a la comunidad, cuya cultura y supervivencia estaban basadas en "lazos de solidaridad, en un sistema de participación comunitario y en una economía pesquera a pequeña escala"62.

Al respecto, la hija de Kimy Pernía Domicó ${ }^{63}$ y uno de los abogados que representaron a la comunidad Embera Katío ante el sistema interamericano de derechos humanos coincidieron en que la Corte se había equivocado en la fórmula adoptada para compensar a las comunidades, pues las compensaciones monetarias individuales no tenían en cuenta la lógica colectiva de la cultura de los Embera Katío ${ }^{64}$. Sobre este punto, Dejusticia explicó que, después de que los indígenas de la comunidad empezaron a recibir las sumas de dinero por concepto de compensación individual, la comunidad no solo empezó a dividirse en la lucha por su territorio, sino que la introducción de las nuevas dinámicas mercantilistas que trajo el dinero de las compensaciones provocó un cambio radical en la cultura de los Embera Katío ${ }^{65}$.

Tal como se mencionó, antes de la construcción de la represa la forma de vida de la comunidad estaba basada en un sistema de participación comunitario y en una economía pesquera a pequeña escala ${ }^{66}$, y el río Sinú, sobre el cual se construyó la represa, constituía su principal fuente de subsistencia. Esto significa que los Embera Katío vivían de acuerdo a lo que algunos autores 'posdesarrollistas' han denominado el 'buen vivir' o la idea del 'sumak kawsay' ${ }^{67}$, en cuanto la comunidad consumía lo que necesitaba y tenía un sentido colectivo de existencia, guiado principalmente por la diversidad y por la vida en armonía con la naturaleza, en oposición a la idea del valor monetario sobre los 'recursos' ambientales.

Con la alteración del curso del río Sinú se produjo una grave afectación para los peces, lo que impactó profundamente la tradición pesquera de los indígenas, su forma de vida y su misma subsistencia. Asimismo, debido a las operaciones de la represa, algunas especies salvajes migraron a otras áreas cercanas al Nudo de Paramillo, de tal manera que no se volvieron a encontrar peces en la parte alta de la cuenca del río Sinú. El transporte por el río también se vio afectado, especialmente debido a que las canoas fueron

62 Ibíd.

63 Ibíd.

64 Orduz-Salinas y Rodríguez-Garavito, Adiós río, cit., 176-177.

65 Ibíd.

66 Ibíd.

67 Gudynas, E. Desarrollo, derechos de la naturaleza y buen vivir después de Montecristi. En Weber, G. Debates sobre cooperación y modelos de desarrollo, Perspectivas desde la sociedad civil en el Ecuador. Quito: Centro de Investigaciones CIUDAD y Observatorio de la Cooperación al Desarrollo, 2011,83-102. 
remplazadas con botes comerciales de motor que cobraban a las personas por el recorrido ${ }^{68}$.

3. REPENSAR LA CONSULTA PREVIA DESDE UNA PERSPECTIVA DECOLONIAL

\author{
3.1. LA RELACIÓN MODERNIDAD-COLONIALIDAD DESDE LA CRÍTICA \\ DECOLONIAL: ¿CÓMO SE REPRODUCEN LOS LEGADOS COLONIALES EN EL \\ DERECHO Y EL ESTADO MODERNOS?
}

Para poder comprender el problema de la ambivalencia de la consulta previa en Colombia resulta clave entender primero el concepto de 'colonialidad' desarrollado por el pensamiento decolonial. A partir de este concepto se explica de qué manera la racionalidad colonial que se instaló a partir de la Conquista en el continente americano, a finales del siglo xv, con la instauración de las administraciones coloniales, guarda un estrecho vínculo con el surgimiento y el desarrollo del capitalismo industrial europeo. Esta noción también plantea que la lógica colonial permanece en nuestros días ${ }^{69}$ y se expresa tanto en términos materiales ${ }^{70}$ como culturales ${ }^{71}$.

68 OrduZ-Salinas y Rodríguez-Garavito. Adiós río, cit.

69 Quisano, A. Coloniality of power and Eurocentrism in Latin America. International Sociology 15.2 (2000) 215-232.

70 Para el grupo modernidad/colonialidad de la crítica decolonial, "la cultura está siempre entrelazada con (y no derivada de) los procesos de la economía política", con lo cual se destaca la estrecha relación entre capitalismo y cultura; pero si bien reconoce el papel fundamental de las epistemes, también sostiene que estas tienen un estatuto económico, apoyándose en la categoría de sistema-mundo. De esta manera, desde la perspectiva decolonial se considera que el capitalismo no solo es un sistema económico ni exclusivamente un sistema cultural, sino que este debe ser comprendido como "una red global de poder integrada por procesos económicos, políticos y culturales, cuya suma mantiene todo el sistema". Grosfoguel, R. y CAStro-Gómez, S. Giro decolonial, teoría crítica y pensamiento heterárquico. En CASTRo-Gómez, S. y Grosfoguel, R. (eds.). El giro decolonial: reflexiones para una diversidad epistémica más allá del capitalismo global. Bogotá: Siglo del Hombre Editores, Universidad Central y Universidad Javeriana, 2007: 16.

71 Sobre este punto, Grosfoguel y Castro-Gómez explican que desde la perspectiva decolonial "no es posible entender el capitalismo global sin tener en cuenta el modo como los discursos raciales organizan a la población del mundo en una división internacional del trabajo, que tiene directas implicaciones económicas: las razas 'superiores' ocupan las posiciones mejor remuneradas, mientras que las 'inferiores' ejercen los trabajos coercitivos y peor remunerados [...] la cultura está siempre entrelazada (y no derivada de) los procesos de la economía política". De esta manera, se destaca la estrecha relación entre capitalismo y cultura, y si bien se resalta el papel fundamental de las epistemes, también se reconoce que estas tienen un estatuto económico. En este sentido, el capitalismo no es considerado solamente como un sistema económico ni exclusivamente como un sistema cultural, sino como "una red global de poder integrada por procesos económicos, políticos y culturales, cuya suma mantiene todo el sistema, a la vez que las estrategias simbólico/ideológicas, así como las formas eurocéntricas de conocimiento, no son aditivas sino constitutivas de la economía política del sistema-mundo capitalista". GROSFOGUEL y CASTRo-GómEz. Giro decolonial, teoría crítica y pensamiento heterárquico, cit., 16-19. 
Desde el campo de los estudios latinoamericanos poscoloniales, también conocidos como 'crítica decolonial', y en particular desde el programa modernidad/colonialidad $(\mathrm{M} / \mathrm{C})^{72}$, "el capitalismo global contemporáneo resignifica en un formato posmoderno las exclusiones provocadas por las jerarquías epistémicas, espirituales, raciales/étnicas y de género/sexualidad, desplegadas por la modernidad. De este modo, las estructuras de larga duración formadas durante los siglos XV y XVII continúan jugando un rol importante en el presente" 73 .

En este sentido, el concepto de 'colonialidad del poder' desarrollado inicialmente por Aníbal Quijano ${ }^{74}$, en diálogo con el enfoque del sistema-mundo de autoría de Immanuel Wallerstein, constituye una poderosa herramienta analítica para comprender las complejas continuidades históricas entre las actuales estructuras y jerarquías políticas y económicas, y los antiguos legados coloniales ${ }^{75}$. En efecto, estas categorías permiten explicar cómo, "aunque se cambie el significado con el tiempo, el predominio de una cultura racista/ colonial global en el sistema-mundo capitalista tiene sus orígenes históricos en la expansión colonial europea" $"$.

72 Héctor Alimonda explica que el programa 'Modernidad/Colonialidad' está en diálogo con el poscolonialismo, los estudios subalternos y la perspectiva sistema-mundo desarrollada por Wallerstein. Sin embargo, el programa M/C también se diferencia de ellos y supone una continuidad de las tradiciones del pensamiento crítico latinoamericano. Este programa se organiza a partir de una crítica de base histórico-cultural y epistemológica de la modernidad y cuestiona las narrativas interpretativas de esta durante cinco siglos. Esta idea supone desplazar los orígenes de la modernidad de su cuna en la Europa del norte. Vinculada a la Reforma protestante, a los orígenes de la acumulación de capital, a la Ilustración o a la Revolución Francesa, y llamar la atención hacia la primera modernidad que protagonizan los reinos ibéricos, junto con su expansión y su conquista ultramarinas. Esto permite visualizar a América como la primera periferia del sistema colonial europeo, el lado oculto originario de la modernidad. Esta racionalidad implica verificar: (i) la racionalidad de las formas estatales y de las empresas coloniales ibéricas; (ii) la acumulación originaria de capital a la que dieron lugar esas conquistas; (iii) la apropiación de la diversidad natural como fundamento de la modernidad; y, (iv) la aparición de los principios de la misión evangelizadora y de la superioridad europea como articulaciones centrales del imaginario colonial eurocéntrico en cuanto sentido común hegemónico de la empresa colonial. El programa $\mathrm{M} / \mathrm{C}$ no se define como opuesto a la modernidad ni niega las potencialidades emancipadoras de esta. Sin embargo, su perspectiva es transmoderna (Dussel) y es crítica con las perspectivas consagradas y consagratorias. El programa $\mathrm{M} / \mathrm{C}$ es un pensamiento de frontera que cuestiona la modernidad noratlántica y se interroga sobre caminos y lógicas alternativos. Véase ALIMONDA, H. Una introducción a la ecología política latinoamericana. En Grosfoguel, R. y AlmanzAHERNÁNDEZ, R. (eds.) Lugares descoloniales. Espacios de intervención en las Américas. Bogotá: Pontificia Universidad Javeriana, 2012: 60-63.

73 Ibíd., 14.

74 QuiJano. Coloniality of power and Eurocentrism in Latin America, cit., 215-232.

75 Grosfoguel, R. Colonialidad del poder y dinámica racial. Notas para la interpretación de los latino-caribeños en Nueva York. En Grosfoguel y Almanza (eds.). Lugares descoloniales, cit., 153.

76 Ibíd. 
Desde esta perspectiva, el territorio americano es entendido como la primera periferia del sistema colonial europeo, por lo que la crítica decolonial propone revisar aspectos como la racionalidad de las formas estatales y de las empresas coloniales, la acumulación originaria del capital a la que dio lugar la conquista de América y la apropiación de la diversidad natural como fundamento de la modernidad ${ }^{77}$. La revisión de estos aspectos también puede contribuir en la comprensión de la permanencia de legados coloniales a través de las formas políticas y económicas contemporáneas, como el Estado moderno y el derecho internacional de los derechos humanos. Asimismo, con el propósito de cuestionar la idea de la descolonización del mundo, la perspectiva decolonial, en diálogo con el sistema-mundo, prefiere hablar de "sistema-mundo euro-norteamericano capitalista patriarcal-moderno/ colonial" 78 y no solamente de sistema-mundo capitalista.

Bajo la categoría de 'colonialidad del poder' se resaltan tres elementos esenciales: (i) el poder colonial; (ii) la división internacional del trabajo, y (iii) los procesos de acumulación capitalista. A partir de estos elementos se pretende explicar las relaciones históricas entre los pueblos 'occidentales' y 'no-occidentales', así como la forma en que "se integran las múltiples jerarquías del poder de capitalismo histórico como parte de un mismo proceso histórico-estructural heterogéneo"79.

Sobre este punto, Grosfoguel y Castro-Gómez explican:

Al centro de la colonialidad del poder está el patrón de poder colonial, que constituye la complejidad de los procesos de acumulación capitalista articulados en una jerarquía racial/étnica global y sus clasificaciones derivativas de superior/ inferior, desarrollo/subdesarrollo, y pueblos civilizados y bárbaros. Igualmente la noción de colonialidad vincula el proceso de colonización de las Américas y la constitución de la economía-mundo capitalista como parte de un mismo proceso histórico iniciado en el siglo xvI. La construcción de la jerarquía racial/étnica global fue simultánea y contemporánea espacio-temporalmente con la constitución de una división internacional del trabajo organizada en relaciones centro-periferia a escala mundial [...] desde la formación inicial del sistema-mundo capitalista se mezcló de manera compleja con los discursos racistas, homofóbicos y sexistas del patriarcado europeo ${ }^{80}$.

77 Alimonda, H. Una introducción a la ecología política. Grosfoguel y Almanza (eds.). Lugares descoloniales, cit., 61.

78 Grosfoguel, R. The Implications of Subaltern Epistemologies for Global Capitalism: Transmodernity, Border Thinking and Global Coloniality. En ApPelbaum, R. P. y Robinson, W. I. (eds.). Critical Globalization Studies. Routledge, 2005.

79 Ibíd., 19.

80 Ibíd. 
Otro de los aspectos más relevantes que corresponde considerar desde esta perspectiva es la comprensión de la conquista de América como el momento en el que se dio inicio al periodo de la modernidad, de la mano de la colonialidad. Grosfoguel afirma que la colonialidad y la modernidad son "dos caras de la misma moneda", siendo la colonialidad la otra cara de la modernidad ${ }^{81}$.

Contrario a lo que se suele creer, el proyecto colonial que se instaló con la conquista de América no fue abolido en un momento histórico determinado con la eliminación formal de las administraciones coloniales, sino que el proyecto moderno/colonial permanece hasta nuestros días, como expresión de la colonialidad, $\mathrm{y}$ ha podido tener continuidad a través de diversas instituciones como el asimilacionismo, el integracionismo, el multiculturalismo, el liberalismo y el constitucionalismo ${ }^{82}$.

De esta manera se explica cómo diversos legados coloniales se han adaptado a la lógica de distintas instituciones modernas y de las estructuras políticas y económicas que las soportan, mientras que estas han legitimado el uso del poder coercitivo del derecho en favor de un pensamiento 'único', 'moderno' y 'universal'.

Otro de los elementos clave para explicar la continuidad de la lógica colonial hasta nuestros días durante varios siglos de expansión colonial europea, a partir del concepto de la 'colonialidad' y su relación con el desarrollo del capitalismo industrial europeo, es la idea de superioridad de una raza sobre otras $^{83}$ y de la jerarquización étnico-racial de las poblaciones. Esta idea ha permitido dar continuidad a una organización del mundo basada en la división internacional del trabajo entre centros y periferias ${ }^{84}$, a través de diversas instituciones modernas como las que se enmarcan en la democracia liberal.

Con esto se explica que para poder llevar a cabo la empresa de la colonización y para poder instaurar el paradigma de la superioridad europea de la mano de las ideas del 'progreso' y del 'desarrollo' fue necesario crear ciertos dispositivos epistemológicos de dominación. En este sentido, Quijano afirma

81 Grosfoguel. La descolonización de la Economía Política y los Estudios Postcoloniales, cit., 27.

82 Mazariegos, M. Derecho a la consulta y disenso. Por el uso contra hegemónico del derecho. Tesis doctoral, Universidad Carlos III de Madrid, 2014: 216-259, disponible en: http://e-archivo.uc3m.es/bitstream/handle/10016/19134/monica_mazariegos_tesis.pdf?sequence $=1$

83 Sobre la importancia del elemento de la raza en los proyectos coloniales, los teóricos poscoloniales latinoamericanos o los críticos decoloniales coinciden con Fanon en la idea de que el mundo colonial se ha estructurado a partir de la idea de raza, siendo este un elemento determinante de la posición de los sujetos en las jerarquías del sistema económico mundial. En efecto, para Fanon la raza es un principio ordenador de las relaciones sociales, incluyendo las económicas, de tal manera que la cultura como instrumento de dominación en contextos coloniales no pueden considerarse simplemente un reflejo de la estructura económica, sino que es constitutiva de esta. Véase FAnon, F. Los condenados de la tierra. México: Fondo de Cultura Económica, 1983. (Título original: Les damnés de la terre). Paris: Maspero, 1961.

84 Grosfoguel y Castro-Gómez, Giro decolonial, teoría crítica y pensamiento heterárquico, cit., 14 . 
que "la dominación y explotación económica del Norte sobre el Sur se funda en una estructura étnico-racial de larga duración constituida desde el siglo XVI por la jerarquía europeo vs. no-europeo" 85 .

Sobre este punto en particular, Quijano y Wallerstein explican que la existencia del sistema-mundo capitalista no sería posible sin la existencia del continente americano y de lo que este representa, ya que como consecuencia de los 500 años de dominación y de expansión colonial europea se ha podido consolidar una división internacional del trabajo entre europeos y no europeos, que persiste actualmente en el sistema mundo capitalista y (pos) colonial $^{86}$.

En este sentido, nociones como las de 'soberanía estatal', 'progreso', 'unidad nacional', 'interés general', 'propiedad privada', 'regalías', entre otras, han sido articuladas a través de la configuración de un sistema legal 'moderno' que arrastra consigo jerarquías y profundos sesgos coloniales.

Algunos de esos legados coloniales se explican, por un lado, por la forma en que se constituyeron los Estados nacionales en América Latina, de acuerdo con una posición subordinada en el marco del sistema-mundo capitalista ${ }^{87}$; y por otro lado, por la manera en que fueron organizados los nuevos Estados de acuerdo a una división jerárquica e internacional del trabajo. Al respecto, Quijano y Wallerstein afirman:

85 Ibíd., 17.

86 Grosfoguel. Colonialidad del poder y dinámica racial, cit., 127.

87 La posición subordinada de los Estados nacionales emergentes en América Latina, en el marco de un sistema-mundo capitalista, es una de las ideas clave de los críticos decoloniales, quienes han aclarado que se separan de los teóricos de la dependencia sobre la manera como debe abordarse este problema. Según la crítica decolonial, los teóricos de la dependencia reproducen la idea ilusoria de que 'una organización y un desarrollo racional' podrían alcanzarse si se le devuelve el control al Estado-nación en un sistema global. Para los teóricos decoloniales, esta posición contradice la idea de que el desarrollo y el subdesarrollo son el resultado de relaciones estructurales en el marco del sistema-mundo capitalista, pues no es posible definir el capitalismo como un sistema global más allá del Estado-nación, y al mismo tiempo sostener que es viable romper con el sistema-mundo desde el Estado-nación. En este sentido, la crítica decolonial es escéptica sobre las posibilidades de transformar un sistema que opera a escala global, simplemente haciendo que los Estados nacionales recuperen el control de su administración. Para los decoloniales, de la recuperación por parte de los Estados nacionales del control 'racional' sobre su soberanía o sus recursos no se deriva automáticamente la afectación en la ubicación de un país en la jerarquía de la división internacional del trabajo que organiza el sistema-mundo. Siguiendo a Wallerstein, Grosfoguel explica que si bien, en el marco del sistema-mundo capitalista, un Estado-nación periférico podría llegar a transformar su forma de incorporarse en la economíamundo capitalista, y alcanzar una posición semi-periférica, no es posible romper o transformar todo el sistema desde el nivel del Estado-nación. Con esto se quiere señalar que una solución local o nacional no es suficiente para un problema global, sin que con ello se niegue la importancia de las acciones políticas a nivel local. Véase Grosfoguel, R. Decolonizing Poscolonial Studies and Paradigms of Political Economy: Transmodernity, decolonial thinking and Global Coloniality. Journal of Peripheral Cultural Production of the Luso-Hispanic World 1.1 (2011) 21-23; Grosfoguel, R. Developmentalism, Modernity and Dependency Theory in Latin America. En Coloniality at large: Latin America and the Postcolonial Debate. Duke University Press, 2008: 322. 
Ethnicity was the inevitable cultural consequence of coloniality. It delineated the social boundaries corresponding to the division of labour. And it justified the multiple forms of labour control, invented as part of Americanity; slavery for the Black Americans. Various forms of coerced cash-crop labour (repartimiento, mita, peonage), indentured labour (engages) for the European working class. These of course were the early forms of ethnic allocation to position in the work hierarchy. In the post-independence period, the forms of labour control and the names of the ethnic categories were updated. But an ethnic hierarchy remained ${ }^{88}$.

Diversas categorías modernas que se han cristalizado en formas jurídicopolíticas han sido construidas históricamente por medio de ejes binarios como capital/trabajo, europeo/no europeo, hombre/mujer; y a través de estos ejes, las élites criollas han podido homogeneizar y clasificar socialmente a los diversos grupos pertenecientes a los Estado-nación del Sur global ${ }^{89}$.

En efecto, las élites criollas que tomaron el control de las estructuras económicas, políticas y culturales, en el tránsito de los imperios europeos a los nuevos Estados independientes, permitieron dar continuidad a varias de las relaciones de poder que se trasladaron del momento colonial al momento (pos)colonial. Estas relaciones permitieron seguir clasificando a la población y excluir a grupos marginados como ciudadanos de segunda categoría considerados como 'minorías' dentro de un imaginario de 'nación' 90.

Esto fue posible gracias a la 'colonialidad del poder', entendida como una relación sociocultural entre europeos y no europeos, que a su vez sigue siendo reproducida de manera continua por las élites criollas, y que responde a la construcción cultural que permanece, de los no europeos como 'otros inferiores ${ }^{\prime 91}$.

Cabe recordar que las primeras constituciones latinoamericanas incluyeron pactos con las élites criollas para que estas pudieran mantener sus propiedades y obtener de esta manera la protección sobre las mismas a través del derecho emanado de las nuevas repúblicas. En este sentido, el rol de las oligarquías que gobernaron los Estados emergentes en Latinoamérica después de que las administraciones coloniales fueran abolidas formalmente, fue determinante para poder garantizar la continuidad de racionalidades coloniales bajo un derecho 'moderno' marcado con un fuerte sello eurocéntrico, jerárquico y hegemónico.

Así, en el tránsito de los regímenes coloniales europeos hacia las repúblicas latinoamericanas que surgieron con posterioridad a los procesos de

88 QuiJano, A. y W ALLERSTEIn, I. Americanity as a concept; or, the Americas in the modern world. International Social Science Journal 134, 1992, 551.

89 Grosfoguel. Developmentalism, Modernity and Dependency Theory in Latin America, cit., 328.

90 Ibíd.

91 Ibíd. 
independencia, las nuevas entidades políticas arrastraron consigo fuertes sesgos coloniales, que permitieron mantener jerarquías propias de la Colonia aunque transformadas, y que posteriormente se verían reflejadas en los nuevos gobiernos.

Sobre este punto, Grosfoguel explica que en el periodo posterior a los procesos independentistas en América Latina, las formas coloniales no capitalistas de trabajo forzado y las jerarquías étnico/raciales fueron mantenidas por las élites criollas. De esta manera, en el marco de las relaciones que se establecieron con los indios, negros, mestizos, mulatos y con otros grupos históricamente oprimidos en el momento posterior a la independencia, se ubicó a estos grupos en la periferia de los Estados emergentes ${ }^{92}$.

El colaboracionismo de las élites criollas, quienes reproducirían al interior de las repúblicas las jerarquías coloniales ${ }^{93}$, fue fundamental para darle continuidad a la lógica colonial a través de las nuevas instituciones 'modernas'. En diálogo con Frantz Fanon, la crítica decolonial ha señalado sobre este aspecto que el acelerado ritmo de la explotación capitalista de la tierra y de la fuerza de trabajo fue facilitado en varias ocasiones por las élites neocoloniales que pertenecían a los mismos grupos oprimidos ${ }^{94}$.

Al respecto, Grosfoguel llama la atención sobre la importancia de la diferenciación entre la 'ubicación epistémica' y la 'ubicación social' de los sujetos en el mundo y afirma:

El hecho de que se esté ubicado socialmente en el lado oprimido de las relaciones de poder no significa automáticamente que se esté pensando epistémicamente

92 Grosfoguel. Developmentalism, Modernity and Dependency Theory in Latin America, cit., 309.

93 Este fenómeno también se ha denominado como 'nordomanía' o northernmania y se refiere específicamente al intento de las élites criollas de las periferias de imitar los 'nuevos' modelos de desarrollo provenientes del Norte, mientras se seguían reproduciendo formas de colonialismo. Sobre el origen de esta expresión, Grosfoguel explica que durante el siglo XIX, Gran Bretaña se había convertido en el nuevo centro de poder en el mundo y en el referente de un nuevo modelo de civilización. Así. Varias de las élites latinoamericanas establecieron un discurso donde contraponían 'el atraso, el oscurantismo y el feudalismo' de España a una idea de nación a seguir 'avanzada, civilizada y moderna' proveniente de Gran Bretaña. Así, bajo la noción de 'nordomanía' se pretende explicar de qué manera la caracterización de las sociedades de la periferia como sociedades del pasado, pre-modernas o subdesarrolladas, por parte de las élites criollas latinoamericanas, permitió justificar la subordinación de los Estados-nación poscoloniales al capital global durante los siglos XIX y Xx. Este fenómeno también implica la negación en el tiempo y en el espacio de la coexistencia de diferentes formas de producir conocimiento o de lo que la crítica decolonial ha llamado 'la negación de la coetaneidad en el tiempo'. Véase Grosfoguel y CASTRo-Gómez. Giro decolonial, teoría crítica y pensamiento heterárquico, cit., 15; Grosfoguel. Developmentalism, Modernity and Dependency Theory in Latin America, cit., 309; ZeA, L. América Latina en sus ideas. UnEsCo y Siglo XXI, 1986.

94 Torres-Maldonado, N. Thinking through the Decolonial Turn: Post-continental Interventions in Theory, Philosophy, and Critique. An Introduction. Journal of Peripheral Cultural Production of the Luso-Hispanic World 1.2, 2011, 3. 
desde una posición epistémica subalterna. Precisamente el éxito del sistemamundo moderno/colonial consiste en hacer que sujetos ubicados socialmente en el lado oprimido de la diferencia colonial piensen sistemáticamente como los que se encuentran en las posiciones dominantes ${ }^{95}$.

El hecho de que los gobernantes de las nuevas repúblicas que pretendían materializar un pensamiento liberal no se lograran despojar de su mirada colonial, al ejercer su labor de gobernar a través de las nuevas entidades políticas y de las estructuras económicas que las sostenían, explica que en las nuevas entidades independientes se hayan interiorizado las jerarquías propias de la lógica colonial. Al respecto, Stuart Hall, señala:

Lo poscolonial está caracterizado por la independencia del gobierno colonial directo, la formación de nuevos Estados nacionales, el crecimiento económico, el incremento del capital local y de las relaciones de dependencia neocoloniales del mundo capitalista desarrollado, así como también por las políticas que surgen con la emergencia de poderosas élites locales que controlan los efectos contradictorios del subdesarrollo [...] tal transición (colonial-poscolonial) está caracterizada por la persistencia de muchos de los efectos de la colonización, solo que ahora estos han sufrido una dislocación: se ha corrido el eje colonizador/colonizado se corre y se han interiorizado en la misma sociedad descolonizada ${ }^{96}$.

Quijano y Wallerstein sostienen que para poder establecer una economíamundo capitalista fueron necesarios tres presupuestos. En primer lugar, la expansión territorial y geográfica del mundo occidental; en segundo lugar, el desarrollo de diversos métodos de control sobre la fuerza de trabajo en beneficio de diferentes productos y zonas de la economía-mundo; y en tercer lugar, la creación de maquinarias estatales relativamente fuertes que se convertirían en los núcleos estatales de la economía-mundo capitalista ${ }^{97}$.

Estos presupuestos permiten explicar cómo las relaciones sociales de poder se han seguido reorganizando y redefiniendo en clave colonial muchos siglos después de la expansión colonial de Occidente y de la abolición de formas propias de los regímenes coloniales ${ }^{98}$. Grosfoguel llama la atención sobre el hecho de que en la era (pos)colonial el colonialismo haya sido reemplazado por la colonialidad, aunque la llamada ‘descolonización del mundo' oscurezca

95 Grosfoguel. La descolonización de la Economía Política y los Estudios Postcoloniales, cit., 22.

96 Hall, S. "When was the post-colonial? Thinking at the Limit". Chambers, Iain, and Lidia Curti. The post-colonial question: Common skies, divided horizons. Routledge, 1996, 303-304.

97 QuiJano y Wallerstein, Americanity as a concept; or, the Americas in the modern world-world system, cit., 549.

98 Ibíd. 
las continuidades entre el pasado colonial y las actuales jerarquías colonialraciales globales, y a la vez invisibilice la colonialidad actual ${ }^{99}$.

La relación entre la colonialidad y la modernidad pone en evidencia la situación colonial de explotación y dominación formada durante años de colonialismo europeo, que como se explicó en líneas anteriores, persiste hasta nuestros días por medio de instituciones juídicas y políticas contemporáneas, a pesar de la erradicación formal de las administraciones coloniales del sistema-mundo capitalista ${ }^{100}$.

Así, a pesar de la erradicación de las instituciones propias del colonialismo, los legados coloniales, sus prácticas e imaginarios han podido permanecer a través del tiempo y del espacio, dando lugar con ello a una transición del colonialismo moderno a la 'colonialidad global', donde el concepto de colonialidad del poder se extiende más allá del Estado-nación a escala global ${ }^{101}$. Por medio de dicho proceso se han "transformado las formas de dominación desplegadas por la modernidad, pero no la estructura de las relaciones centroperiferia a escala mundial" ${ }^{102}$.

Castro-Gómez y Grosfoguel explican que si bien el fin de la Guerra Fría terminó con el colonialismo de la modernidad, dio inicio al proceso de la colonialidad global. Al respecto sostienen que "nuevas instituciones del capital global, tales como el Fondo Monetario Internacional (FMI) y el Banco Mundial (BM), así como organizaciones militares como la OTAN [...] todas conformadas después de la Segunda Guerra Mundial y del supuesto fin del colonialismo, mantienen a la periferia en una posición subordinada" ${ }^{103}$.

La comprensión de diversas categorías modernas como expresiones de la colonialidad permite poner en tela de juicio su carácter emancipatorio y 'moderno', a la vez que hace posible explicar cómo a través de mecanismos propios de las entidades políticas modernas que se presentan como emancipatorias, como es el caso del Estado moderno o del derecho internacional de los derechos humanos, se continúan reproduciendo legados coloniales que ponen en tela de juicio ideas como la 'autodeterminación', que dentro de las narrativas jurídicas y políticas modernas provenientes del pensamiento liberal aparecen como elementos distintivos entre la colonia y el Estado.

Así, partiendo de la idea de que la modernidad no es un estado posterior ni superior a la colonialidad, en donde esta última sería trascendida por aquella, sino que la modernidad y la colonialidad se constituyen mutuamente desde el momento mismo de la conquista de América, se pretende explicar cómo

99 Grosfoguel. "Colonialidad del poder y dinámica racial, cit., 128.

100 Ibíd., 126.

101 Ibíd., 136.

102 Grosfoguel y CASTRO-Gómez. Giro decolonial, teoría crítica y pensamiento heterárquico, 13.

103 Ibíd. 
a través de los mecanismos y dispositivos propios del Estado moderno se terminan reproduciendo y reactualizando legados coloniales.

\section{La colonialidad de la naturaleza}

Bajo la categoría de la colonialidad también se ha cuestionado la comprensión de la naturaleza como espacio/objeto de extracción. Según Alimonda, la lógica extractiva, entendida como una manifestación de la 'colonialidad del poder' sobre la naturaleza, permite comprender cómo esta ha sido comprendida desde la época de la Colonia como un espacio de extracción, que en nuestros días adopta la forma de "la hiperminería a cielo abierto; de los monocultivos de soja y los agro combustibles con insumos químicos que arrasan ambientes enteros -inclusive a los humanos-, de los grandes proyectos hidroeléctricos o de las vías de comunicación en la Amazonía, como infraestructura de nuevos ciclos exportadores" 104 .

Bajo esta idea, la naturaleza y específicamente los recursos naturales y las tierras tropicales, fueron fundamentales en los espacios coloniales para la génesis y el desarrollo de la modernidad. Alimonda destaca que la modernidad capitalista, desde sus inicios, se produjo como consecuencia de transacciones transcontinentales, explicando con esto que el carácter global de la modernidad se originó desde la Conquista y desde el proceso de colonización de las Américas ${ }^{105}$.

Partiendo de la noción de 'descubrimientos imperiales' de Boaventura de Sousa Santos ${ }^{106}$, Alimonda sostiene que este tipo de descubrimientos siempre supone la producción de dispositivos que ponen en situación de inferioridad y subordinación lo descubierto, para así colonizarlo y explorarlo, ya se trate del 'Oriente', de los 'salvajes' o de la 'naturaleza tropical' ${ }^{107}$.

En el caso de América, los colonizadores destruyeron la biodiversidad de la naturaleza para implantar monocultivos de especies tóxicas de exportación, lo cual constituye un ejemplo de lo que Polanyi ${ }^{108}$ definió como la transformación de la naturaleza a la tierra. Así, este tipo de colonialidad de la naturaleza se continúa repitiendo en el siglo XxI con fenómenos como la expansión de los monocultivos de soja y los agrocombustibles, y la realización de proyectos extractivos a gran escala donde generalmente habitan poblaciones y grupos

104 Alimonda, H. La colonialidad de la naturaleza. Una aproximación a la ecología política latinoamericana. En Alimonda, H. (coord.). La naturaleza colonizada. Ecología política y minería en América Latina. Clacso, 2011, 22.

105 Ibíd., 47.

106 De Sousa Santos, B. Conocer desde el Sur. Lima: Universidad Nacional Mayor de San Marcos, 2006, 117-128.

107 Ibíd.

108 Polanyi, K. La gran transformación. Crítica del liberalismo económico. Quipu Editorial, 2007, 289-308. 
considerados 'minoritarios' dentro del Estado-nación y que tienen una forma diferente de relacionarse con la naturaleza ${ }^{109}$.

En este orden de ideas, desde la crítica decolonial en general, y desde el programa 'Modernidad/Colonialidad' en particular, se ha hecho énfasis en la idea de que los países de América Latina siempre han sido considerados espacios de extracción. En este sentido es que Mignolo se ha referido a la relación del origen del 'mito de la modernidad' con el descubrimiento de América y ha explicado que, a diferencia de los países europeos, donde había un espacio interno por nacionalizar, las sociedades americanas tenían un espacio por colonizar. Por ello se afirma que el proceso de centralización estatal anterior a la formación de los Estados-nación se presentó de manera paralela a la imposición de proyectos coloniales.

Igualmente, con el proceso independentista en América Latina, los Estados que habían sido colonias, siguiendo los discursos eurocéntricos liberales dominantes, construyeron ideologías de identidad nacional, desarrollo nacional y soberanía nacional, que produjeron una ilusión de independencia, desarrollo y progreso ${ }^{110}$. Sin embargo, tal como se explicó en líneas anteriores, los sistemas económicos y políticos de los Estados emergentes fueron moldeados por su posición subordinada en el sistema-mundo capitalista, organizado en torno a una división internacional del trabajo jerárquica, donde los recursos naturales han jugado un papel fundamental.

De manera similar a lo que ocurrió en tiempos coloniales bajo el 'mito de la modernidad', en la actualidad, bajo discursos incorporados en las instituciones políticas y jurídicas del Estado moderno, se ha legitimado una idea de progreso que se presenta como hegemónica y que deja de lado formas diversas de comprensión del 'desarrollo'. Esta mirada hegemónica del desarrollo envuelve una división entre sociedades superiores (desarrolladas) y sociedades inferiores (subdesarrolladas) donde estas últimas deben alcanzar los estándares de las primeras y lograr así su inclusión en el orden económico global.

En este sentido, la crítica decolonial resalta el hecho de que los Estadosnación desarrollaron estrategias de tipo ideológico y simbólico, que fueron incorporadas a sus estructuras jurídicas mediante la imposición de discursos que privilegiaron la cultura 'occidental' sobre todas las demás, y en particular por medio de "un discurso desarrollista que ofrece una receta colonial de cómo imitar a Occidente" 111 . Esto explica que "Europa/Euro-Norteamérica son pensadas como viviendo una etapa de desarrollo (cognitivo, tecnológico

109 Alimonda. La colonialidad de la naturaleza. Una aproximación a la ecología política latinoamericana, cit., 47.

110 Grosfoguel, Colonialidad del poder y dinámica racial, cit., 128.

111 Grosfoguel y CASTRo-Gómez. Giro decolonial, teoría crítica y pensamiento heterárquico, cit., 20. 
y social) más avanzada que el resto del mundo, con lo cual surge la idea de superioridad de la forma de vida occidental sobre todas las demás. Europa es el modelo a imitar y la meta desarrollista era (y sigue siendo) alcanzarlos" 112 .

De esa manera, las comprensiones sobre el 'progreso' y el 'desarrollo' hegemónicas que se han cristalizado a través de diversas formas jurídicas y estatales tienen una incidencia directa sobre la relación que se establece en las (pos)colonias con la naturaleza y con los usos que se le dan a esta.

En palabras de Machado Aráoz, "la fenomenología de la novedad y el cambio, señales inequívocas y evidentes del 'progreso', alientan y alimentan la fantasía primer-mundista de gobernantes y defensores a ultranza de la minería, 'madre de industrias' y 'motor de desarrollo' [...] obras y cemento que sin mucho ton ni voz van revistiendo con aires de modernidad el atraso y la pobreza históricos" ${ }^{\prime 13}$.

\subsection{LAS LIMITACIONES DE LA CONSULTA PREVIA COMO CONTINUIDADES DEL RÉGIMEN COLONIAL A TRAVÉS DE INSTITUCIONES JURÍDICO- POLÍTICAS DE RAIGAMBRE LIBERAL}

Repensar la consulta previa desde una perspectiva decolonial implica cuestionar el sesgo colonial de dicho instrumento y el alcance limitado tanto del diálogo como del 'consenso' que implica el proceso de la consulta previa. Como se mencionó en líneas anteriores, dicho sesgo se ve reflejado en la paradoja que Merino ha denominado de 'inclusión/exclusión'. Esta paradoja implica que los pueblos indígenas deben ser 'reconocidos' por el mismo Estado, quien a su vez es el ente que debe autorizar el diálogo con las autoridades y con otros actores 'occidentales', pero solamente sobre ciertos aspectos definidos por estos y con la condición de que el resultado obtenido con el proceso de consulta no es vinculante per $s e^{114}$.

112 Ibíd., 15.

113 Machado ArÁoz, H. El auge de la minería transnacional en América Latina. De la ecología política del neoliberalismo a la anatomía política del colonialismo. En AlimondA (coord.) La naturaleza colonizada, cit., 136.

114 "The Special Rapporteur on the Situation of Human Rights and Fundamental Freedoms of Indigenous Peoples, James Anaya, stated that the issue of state power in relation to prior consultation with indigenous peoples cannot be appropriately treated, focusing on the question of whether there is or not a veto by the indigenous peoples. According to Anaya, the indigenous peoples could be justified not to consent, not on a unilateral veto, but as long as the state does not adequately demonstrate that the rights of the indigenous peoples affected were adequately protected under the measure or proposed project, or not prove that substantial negative impacts were properly mitigated". Declaración pública del Relator Especial sobre los Derechos Humanos y Libertades Fundamentales de los Indígenas, James Anaya, sobre la Ley del Derecho a la Consulta Previa a los Pueblos Indígenas u Originarios reconocido en el Convenio 169 de la orT, aprobada por el Congreso de la República del Perú el 7 de julio de 2010. Disponible en: http:// unsr.jamesanaya.org/statements/declaracion-sobre-la-ley-del-derecho-a-la-consulta-previa-alos-pueblos-indigenas-peru-7-julio-2010 
En este sentido, se cuestiona el alcance de la consulta previa como una institución que está inmersa en un sistema ligado al pensamiento liberal, que a su vez reproduce legados coloniales y que sirve como un instrumento de gobernanza global. Mazariegos explica que uno de los aspectos más problemáticos de la consulta es que esta institución ha terminado por adecuarse a poderosos discursos que hasta cierto punto han logrado ajustarse en algunos casos a la racionalidad económica dominante, como ocurre con el lenguaje de los derechos humanos. La autora explica que este lenguaje se ha vuelto cada vez más sofisticado gracias a instrumentos como los códigos de conducta de las compañías transnacionales, los Principios de la Organización de Naciones sobre Empresa y Derechos Humanos y el llamado soft law emanado de las organizaciones financieras internacionales ${ }^{115}$.

En el marco del diálogo que se produce en el proceso de consulta previa, temas como el 'modelo de desarrollo' no pueden ser objeto de discusión. Esta restricción conduce a que genuinos intereses de los grupos indígenas, como los que corresponden a las nociones de 'territorialidad' y 'autodeterminación', resulten excluidos de dicho diálogo ${ }^{116}$. Asimismo, en razón de las condiciones propias en que se promueve el proceso de consulta previa, las autoridades nacionales son quienes terminan determinando la agenda del diálogo que se promueve en el marco de dicho proceso. En efecto, cual ocurrió en el caso del proyecto minero de Mandé Norte atrás explicado, las autoridades nacionales generalmente no reconocen como válido el proceso de consulta previa que es promovido y llevado a cabo por las mismas comunidades indígenas, argumentando que el Estado es el único sujeto autorizado para liderar dicho proceso.

Sin embargo, resulta cuestionable esta restricción, sobre todo teniendo en cuenta que en la práctica son otros actores privados interesados en obtener ciertos resultados de la consulta, como las compañías transnacionales, los que en la práctica terminan liderando dicho proceso, sin que en esos casos sea considerada la consulta inválida por las autoridades gubernamentales. Este problema es explicado por Merino en los siguientes términos:

Todo el proceso de la consulta previa es diseñado como un mecanismo para informar y convencer a los pueblos indígenas de una decisión que ha ya sido tomada

115 Mazariegos, M. Derecho a la consulta y disenso. Por el uso contra hegemónico del derecho. Tesis de doctorado, Universidad Carlos III de Madrid, 2014. Disponible en: http://earchivo.uc3m.es/bitstream/handle/10016/19134/monica_mazariegos_tesis.pdf?sequence $=1$. Véase también Hernández Zubizarreta, Juan. ¿'Lex mercatoria' o derechos humanos? Los sistemas de control de las empresas transnacionales. En Hernández ZubizARRETA, J. y RAMIRo, P. (eds.). El negocio de la responsabilidad. Crítica de la Responsabilidad Social Corporativa de las empresas transnacionales. Icaria, 2009.

116 Merino. Coloniality and Indigenous Territorial Rights in the Peruvian Amazon: A Critique of the Prior Consultation Law, cit., 11-12. 
de antemano por el Estado; el diálogo 'intercultural' solo aparece si los pueblos indígenas no logran ser persuadidos. ¿Pero esto no debería ser al contrario? El diálogo intercultural debería ser la primera fase del proceso liderado por un Estado realmente respetuoso de los pueblos indígenas, en orden a identificar las prioridades de estos pueblos así como sus necesidades y aspiraciones, lo cual contribuiría a su vez a enriquecer el diálogo mutuamente ${ }^{117}$ (trad. mía).

Desde una perspectiva decolonial, el problema sobre la forma en la que es conducido el diálogo en el marco del proceso de la consulta previa también denota una forma de racismo epistémico y estructural. Esto se explica porque la lógica de la consulta previa asume que las autoridades nacionales que representan al sistema occidental saben de antemano qué es lo mejor para los 'otros'. Esta lógica a la larga termina justificando el uso de la violencia contra los que piensan 'diferente', que además son considerados simplemente como grupos 'minoritarios'. Así, históricamente se ha aceptado el uso de la violencia contra los grupos indígenas no solo de forma física sino en la forma de violencia 'epistémica' a través de discursos como los de la 'modernidad', el 'progreso', el 'desarrollo', los cuales se han podido insertar a través del pensamiento liberal y a su vez han terminado justificando diferentes tipos de exclusión.

Por su parte, la retórica (neo)colonial que subyace a la consulta previa no interroga las presunciones del pensamiento liberal que están inmersas en este instrumento, como por ejemplo la comprensión de los pueblos indígenas como 'minorías' y las implicaciones que derivan de este reconocimiento; el respeto por los territorios indígenas en la medida que se les dé a estos un uso 'eficiente' de acuerdo al modelo de desarrollo económico dominante; o la ambigüedad del carácter vinculante de la decisión adoptada por las comunidades como resultado del proceso de consulta.

En esta medida se habla de una retórica (neo)colonial, puesto que la consulta termina reproduciendo la lógica de acuerdos llevados a cabo desde tiempos coloniales, según los cuales los pueblos indígenas terminaban por aceptar de manera 'voluntaria' la autoridad de la Corona española sobre sus territorios. En dicho contexto, cuando los pueblos indígenas rechazaban las condiciones impuestas por la Corona, debían afrontar la declaración de 'guerra justa', y si llegaban a sobrevivir a esta podían ser convertidos en esclavos ${ }^{118}$.

La ambivalencia de los instrumentos del derecho moderno para proteger los territorios de los pueblos indígenas proviene de tiempos coloniales. Por ejemplo, Francisco de Vitoria, reconocido como uno de los padres del derecho internacional por desarrollar el concepto de igualdad ligado al concepto

117 Ibíd., 10.

118 Dussel, E. D. y BARber, M D. The invention of the Americas (New York: Continuum, 1995). 
de dignidad humana, nociones que fueron clave para abolir la esclavitud, también avaló otras nociones como las de 'guerra justa' y 'justos títulos', que a su vez fueron indispensables para justificar la conquista como un acto "civilizatorio" ${ }^{119}$. Al respecto, Barreto señala:

Reconocer a Vitoria como uno de los precursores de la teoría moderna del derecho natural y de los derechos humanos puede ser una construcción algo confusa e incluso desconcertante, dado que en el derecho natural los derechos reposan principalmente en el poder absoluto del emperador y en la hordas de conquistadores, y ser racional y por lo tanto ser reconocido como sujeto de acuerdo al derecho natural y al derecho internacional constituye la razón misma de ser privado de todo derecho ${ }^{120}$.

Según este autor, para los indios, convertirse en sujetos de derecho bajo la jurisdicción del derecho natural constituía una especie de trampa, debido a que el derecho al que aludía Vitoria pretendía reconocer la humanidad de los pueblos indígenas, pero al mismo tiempo pretendía justificar el ejercicio de diversas formas de violencia en contra de ellos. Barreto explica que para estos pueblos la noción de 'sujetos de derecho' era una noción vacía por la ambigüedad que implicaba en cuanto al reconocimiento de sus derechos ${ }^{121}$.

Sin embargo, la fama adquirida por Vitoria por sus innovaciones en el derecho natural y en el derecho internacional permitió catapultar estos sistemas como modernos y humanistas, a pesar de que a través de ellos también se avalaron diferentes violencias en contra de los indígenas tanto en su forma física como en su forma epistémica.

Por su parte, Anghie, uno de los autores más reconocidos dentro de la corriente TWAIL, también llamó la atención sobre el hecho de que Vitoria haya simplificado el problema de las dos visiones del mundo de los pueblos indígenas y los conquistadores como un problema de 'jurisdicción', lo que le permitió crear toda una narrativa sobre la existencia del derecho natural. $\mathrm{Al}$ respecto Anghie explica:

Los españoles y los indios no estaban unidos por un sistema universal predominante sino que pertenecían a ordenes diferentes, y Vitoria interpreta la brecha entre estos dos órdenes como un problema de jurisdicción. Así, la resolución de este problema es crucial tanto para la nueva jurisprudencia de Vitoria como para la construcción de un marco jurídico común que permitiera resolver el problema

119 Dussel, E. Las Casas. Vitoria and Suárez, 1514-1617. En Barreto, J. M. (ed.). Human Rights from a Third World Perspective: Critique, History and International Law, (Cambridge: Cambridge University Press, 2012).

120 BARRETO, J. M. Imperialism and decolonization as scenarios of human rights. En BARREто (ed.). Human Rights from a Third World Perspective, cit., 150-151.

121 Ibíd. 
de estatus de los indios. Las dos formas a través de las cuales Vitoria aborda el problema de la jurisdicción comprenden dos partes que están relacionadas entre sí: por un lado, la compleja caracterización de la personalidad de los indios, y por otro, la elaboración de un nuevo sistema de derecho natural universal ${ }^{122}$.

Cabe resaltar que Fray Bartolomé de as Casas también es reconocido como una de las voces más críticas del pensamiento colonial y como uno de los primeros defensores de los indios. Al igual que Vitoria, Fray Bartolomé de Las Casas acudió a nociones propias del derecho natural para criticar algunas instituciones que permitían llevar a cabo acciones discriminatorias contra los pueblos indígenas, tales como la servidumbre y la esclavitud.

Ambos autores alegaron que los indios eran seres humanos y que por lo tanto tenían derechos sobre los territorios que habitaban. Asimismo, argumentaron que debían ser reconocidos como grupos o comunidades, teniendo en cuenta su sentido de la colectividad ${ }^{123}$. Particularmente, Fray Bartolomé de Las Casas cuestionó las atrocidades cometidas en contra de los pueblos indígenas a través de instituciones como la 'encomienda' y el 'requerimiento', que fueron unas de las instituciones más opresivas que se utilizaron en la época de la Colonia, a la vez que sirvieron para poder redistribuir las tierras de los indios entre los conquistadores españoles y para garantizar el derecho al 'uso' de quienes habitaban en ellas.

El pensamiento de Las Casas también fue de gran utilidad para llevar a cabo las acciones de evangelización sobre los indios, a través del concepto de 'dominación pacífica'. Esta noción se refiere al diálogo como medio para poder difundir el evangelio entre los pueblos indígenas sin necesidad de acudir al uso de la fuerza y sin poner en tela de juicio los principios de la fe cristiana ${ }^{124}$.

Si bien tanto Vitoria como Las Casas hicieron importantes contribuciones para reconocer la 'condición humana' de los indios, el derecho a la propiedad sobre sus territorios y para que estos fueran reconocidos como grupos o colectividades, también es cierto que para ambos autores fue difícil apartarse de la lógica colonial en la que estaban inmersos. Aunque ambos desempeñaron un rol muy importante para que los abusos y excesos cometidos contra la población indígena fueran minimizados, también apoyaron acciones de colonización por medios más ‘civilizados'. Un ejemplo de ello es que ni Las Casas ni Vitoria cuestionaron el uso de los indios para labores de trabajo forzoso, dado que estas labores eran indispensables para la consolidación de la administración colonial española como proyecto económico.

122 Anghie, A. Imperialism, sovereignty, and the making of international law. Cambridge, UK: Cambridge University Press, 2005, 19.

123 Dussel. Las Casas. Vitoria and Suárez, cit.

124 Ibíd. 
El uso de los indígenas (y de sus territorios) como 'grupos subalternos' ha sido utilizado desde tiempos coloniales para mantener y consolidar el proyecto económico dominante de nuestra época. Si bien es cierto que las campañas de independencia que se llevaron a cabo en el continente latinoamericano, el posterior surgimiento de las repúblicas y la consolidación del constitucionalismo propendieron al desmantelamiento de las administraciones coloniales, también es cierto que varias de las normas emitidas bajo las instituciones políticas modernas han permitido la continuidad de legados coloniales y de formas de racismo epistémico, que a su vez han logrado mantener ciertas estructuras de división del trabajo y formas de acaparamiento de la tierra, útiles al proyecto económico de la modernidad bajo un pensamiento de raigambre liberal.

Clavero señala que la fase de implementación del constitucionalismo representa uno de los periodos de mayor auge del colonialismo, argumentando que la tradición del constitucionalismo, a su vez está precedida y estrechamente conectada con la época republicana, con el surgimiento de un sistema representativo y del pensamiento moderno, por un lado representa el espíritu de la resistencia de la burguesía frente al absolutismo de la monarquía, pero por otro lado envuelve la paradoja de servir para la continuación de jerarquías provenientes de la época colonial ${ }^{125}$.

En este sentido es que se argumenta en este artículo que la lógica de la consulta previa conlleva un profundo sesgo colonial, en la medida que, al igual que ocurrió con ciertas instituciones en tiempos coloniales, actualmente los pueblos indígenas son forzados pacíficamente y a través de medios 'legales' a aceptar un 'consenso' sobre el uso que se debe dar a sus territorios. Asimismo, en caso de oponerse al 'consenso' alcanzado, los grupos pueden ser expulsados por la fuerza de tales territorios.

El uso ambivalente de la consulta previa denota la utilización de esta institución como un medio moderno de 'dominación pacífica' y como un sofisticado instrumento de inclusión/exclusión, que se enmarca en el discurso humanista del derecho de los derechos humanos, pero que al mismo tiempo tiene la capacidad de legitimar actos de exclusión. Mazariegos resalta que los pueblos indígenas son reconocidos como sujetos de derecho siempre y cuando no traspasen ciertos límites que se enmarcan en la lógica de la racionalidad occidental y en el consenso político 'previo' que implica dicha lógica ${ }^{126}$.

Según esta autora, el principal problema de la consulta previa es que este instrumento está inmerso en una racionalidad que tiende a despolitizar a los pueblos indígenas y a negar el conflicto per se, el cual es inherente a cualquier

125 Clavero, B. El orden de los poderes. Historias constituyentes de la trinidad constitucional. Madrid: Trotta, 2007, 245-253.

126 Mazariegos. Derecho a la consulta y disenso, cit. 
sociedad ${ }^{127}$. Esta despolitización se traduce en la reducción del conflicto y del 'diálogo' a los márgenes del ordenamiento legal, el cual, como vimos en el caso de la consulta previa, produce efectos y posibilidades muy restringidas para los pueblos indígenas, incluso cuando el derecho está formalmente a favor de estos. La crítica sobre la despolitización que produce la consulta refleja el escepticismo frente a las posibilidades emancipatorias de la consulta previa, que se explica por las contradicciones, las limitaciones y los efectos restrictivos de la consulta en Colombia, que denotan su uso como un instrumento útil para una racionalidad económica que se presenta como única en un contexto (neo)colonial.

Mazariegos afirma que esa situación también provoca que la consulta previa, como expresión del multiculturalismo y del sistema democrático, se concentre en el consenso como un punto de llegada y no en el disenso como un punto de partida, con lo cual se ignoran las raíces del conflicto y se asume que hay unas minorías que deben 'sacrificarse' en aras del llamado 'interés general', y que, a lo sumo, deben ser compensadas económicamente ${ }^{128}$.

Recordemos lo ocurrido en el caso de la construcción de la represa de Urrá, donde la forma que encontraron los jueces para proteger a las comunidades y reparar el daño causado con dicho proyecto fue reconocer a los miembros de la comunidad, como compensación, el pago por veinte años de una suma individual. Sin embargo, como se explicó, dicha forma de 'proteger' a la comunidad bajo la lógica de la sociedad occidental trajo la ruptura de un sistema cultural colectivo basado en los lazos de solidaridad, que se sumó al impacto causado por la construcción de la represa per se.

De lo anterior se concluye que si bien algunas veces los jueces fallan a favor de los intereses económicos de las grandes compañías transnacionales, y otras a favor de los pueblos y comunidades étnicas o de los grupos minoritarios, los efectos restrictivos de las decisiones judiciales son evidentes incluso cuando se falla a favor de las comunidades.

Cabe recordar que en el caso atrás explicado, de la declaratoria del Parque Nacional Natural Yaigojé-Apaporis, la forma de proteger a los pueblos indígenas con ocasión del proceso de consulta que fue impulsado y auspiciado por la misma compañía minera, fue dejar en firme la declaratoria del parque, la cual es una figura que si bien impide la realización de actividades de minería, también restringe el acceso de los pueblos indígenas a los recursos de flora y fauna para su subsistencia, dado que es una figura jurídica creada bajo una lógica occidental de protección del ambiente.

Finalmente, parafraseando las palabras de Sundhya Pahuja, llama la atención que de conflictos de diversa índole como los atrás descritos estén emergiendo luchas por todo el mundo, luchas en las que modos 'tradicionales' de vida 
se están extinguiendo en el marco de la modernidad global y a la sombra del llamado 'interés general'. Sin embargo, frente a esos conflictos los abogados no tienen otra responsabilidad que ayudar a tratar de resolverlos de acuerdo a la ley y a los marcos jurídicos que emanan de un visión primordialmente 'occidental'. Así, los marcos de referencia para tratar de solucionar esos tipos de conflictos por parte de los operadores jurídicos son principalmente el derecho de los derechos humanos, las normas internacionales relacionadas con los pueblos indígenas y tribales, o los nuevos marcos normativos internacionales que se están desarrollando para guiar el comportamiento de las grandes empresas, especialmente frente a los impactos que estas producen en el Sur global ${ }^{129}$.

\section{CONCLUSIÓN: LA IMPORTANCIA DE DECOLONIZAR \\ LA CONSULTA PREVIA EN COLOMBIA}

Si bien la consulta previa es uno de los instrumentos más reconocidos en el marco del derecho internacional de los derechos humanos, para efectos de proteger a los pueblos y comunidades étnicas esta institución está inmersa en la racionalidad occidental y en el pensamiento liberal que a su vez reproducen ciertos legados coloniales. Esta forma de colonialidad ha traído como consecuencia serios obstáculos para que los pueblos indígenas puedan hacer de la consulta un genuino instrumento emancipatorio y para provocar un verdadero proceso de decolonización. De hecho, tal como se mostró en líneas anteriores, dicha institución ha forzado en algunos casos a miembros de los pueblos y comunidades a proteger sus territorios de forma restringida y en el marco de los estrechos márgenes de la lógica del sistema de derecho moderno occidental.

En un contexto de capitalismo global, en el que el sistema económico está fuertemente basado en la acumulación de recursos y, por lo tanto, en la realización de proyectos extractivos y de infraestructura a gran escala, la consulta previa se ha convertido en uno de los pocos instrumentos que han encontrado los pueblos y comunidades étnicas para defender sus territorios, bajo la lógica del sistema occidental, aunque, como hemos dicho, de manera limitada o temporal. Así, la consulta previa sigue teniendo serias limitaciones como herramienta de decolonización, debido en parte a que a través de esta institución se siguen reproduciendo legados coloniales que a su vez son avalados por la lógica liberal de la que se encuentra imbuida. Por ejemplo, los pueblos indígenas solo son reconocidos como 'otros' y como grupos minoritarios, de manera que bajo la lógica de la democracia liberal, las reivindicaciones de estos pueblos están sujetas a lo que se entienda por 'interés

129 Pahuja, S. Laws of encounter: A jurisdictional account of international law. London Review of International Law. 2013, 1:1, 64-65. 
general'. Verbigracia, a los proyectos que bajo la racionalidad económica dominante promuevan el 'desarrollo'.

Tal como se explicó en las secciones anteriores, el reconocimiento de estos grupos como minoritarios resulta problemático en la medida que sus derechos e intereses solo son respetados si se enmarcan en las categorías propias de la racionalidad occidental como la de 'propiedad privada', cuya lógica original no abarca el sentido colectivo que le imprimen estos pueblos al territorio, ni es comprensiva de la especial relación que los pueblos y comunidades étnicas tienen con la naturaleza.

De manera adicional, de acuerdo a lo señalado en líneas anteriores, la consulta previa solo es reconocida como válida si el proceso de consulta es promovido por las autoridades 'occidentales', hasta el punto de que, como ha ocurrido en la algunos casos, como el del proyecto minero de Mandé Norte atrás explicado, el resultado de la consulta impulsada por las mismas comunidades no es reconocido como vinculante por las autoridades nacionales. Esta restricción resulta especialmente problemática en la medida que reproduce la lógica colonial de que los indígenas son incapaces de pensar y de tomar decisiones por sí mismos.

Desde el pensamiento decolonial, este tipo de restricciones se explican por la existencia de una estructura de poder y una estructura epistémica que está basada en una jerarquía racista, la cual sigue siendo reproducida desde tiempos coloniales. Esto se explica porque la opresión histórica de los pueblos indígenas no fue eliminada a pesar de las voces críticas que emergieron en la época colonial como 'los defensores de los indios'. Por el contrario, el derecho internacional moderno que se reproduce en las facultades de derecho está basado en un fuerte sesgo colonial que a su vez resulta funcional para la consolidación del modelo económico actual.

En tiempos coloniales la ambivalencia de los instrumentos para la defensa de los derechos de los pueblos indígenas en términos de inclusión/exclusión era evidente. Por ejemplo, Francisco de Vitoria defendió la 'condición humana' de los indios pero al mismo tiempo justificó por medio de instituciones 'legales' de la época que aquellos fueran despojados de sus territorios. De manera similar, Las Casas denunció las atrocidades y la violencia física en contra de los pueblos indígenas pero a la vez validó su evangelización mediante la llamada 'dominación pacífica'.

Ese uso ambivalente de los instrumentos para proteger a los pueblos indígenas se repite en nuestros días. Como se explicó a lo largo de este artículo, la consulta previa también ha sido utilizada por grandes actores económicos tales como las compañías transnacionales para ocupar 'legalmente' los territorios donde se encuentran asentados los pueblos y comunidades étnicas. Por otro lado, el debate sobre si la consulta implica o no consentimiento demuestra las limitaciones del carácter 'incluyente' de esta institución en el marco de una democracia liberal. Asimismo, otro de los efectos restrictivos que se deriva 
del uso ambivalente de la consulta previa es la división que este proceso ha causado al interior de las comunidades en algunos casos, incluyendo aquellos en los que la decisión de la consulta les ha resultado favorable inicialmente.

A partir de lo anterior se concluye que el uso ambivalente de la consulta previa envuelve un proyecto moderno de dominación pacífica, que causa un consenso no genuino por medio de un discurso persuasivo bajo la retórica liberal.Además, dicho discurso legitima el uso de la violencia en el caso de que la decisión adoptada por las comunidades exceda los límites de la democracia liberal y cuando los pueblos indígenas decidan reclamar su emancipación en términos de territorialidad y de autodeterminación.

A partir del problema que se expone en este artículo se muestra de qué manera el uso ambivalente de la consulta previa, como un instrumento enmarcado en la idea liberal del multiculturalismo, no envuelve un encuentro genuino en términos de igualdad entre las partes que acuden al diálogo que propone la consulta. Por el contrario, el uso ambivalente de la consulta denota su naturaleza como un mecanismo de persuasión que sigue percibiendo a los pueblos indígenas como los 'otros', quienes además resultan excluidos si no hacen un uso eficiente de sus territorios y no acumulan el suficiente capital requerido por el sistema capitalista.

Con lo anterior se confirma la idea de la paradoja inclusión/exclusión referida por Merino según la cual estos pueblos son incluidos pero solo mediante instrumentos restrictivos; así como lo señalado por Pahuja en el sentido de que permanentemente se descubren nuevas técnicas y prácticas procedimentales de autorización que terminan constituyendo el mundo en nombre del derecho ${ }^{130}$.

Arturo Escobar, uno de los autores más representativos del proyecto Modernidad/Colonialidad atrás explicado, ha resaltado la necesidad de pensar alternativas que sean verdaderamente incluyentes para los pueblos y las comunidades étnicas. En particular, ha señalado la necesidad de imaginar 'otros' mundos posibles en el marco de un 'pluri-verso' en lugar de un 'universo' ${ }^{131}$. Al respecto, este autor resalta las limitaciones de las categorías del derecho moderno para crear las condiciones de posibilidad de 'otros' mundos y explica que "no es posible crear soluciones para un problema bajo las mismas categorías que crearon ese problema"132.

En concordancia con el planteamiento de Escobar, y con base en el problema desarrollado en este artículo, se concluye que para que la consulta

130 Pahuja. Laws of encounter, cit., 96.

131 EscoBAR, A. Conversaciones sobre el sur global: Gobernanza, Extractivismo y Resistencia. Conferencia. Bogotá: Universidad del Rosario, 2015), disponible en: http://www.urosario.edu. co/Home/Principal/Eventos/Facultad-de-Jurisprudencia/Conversaciones-sobre-el-Sur-Global/

132 Escobar, A. Hay que abandonar la idea afanosa del crecimiento. Entrevista. El Espectador, 2 de septiembre de 2015, disponible en: http://www.elespectador.com/noticias/economia/ hay-abandonar-idea-afanosa-del-crecimiento-economico-articulo-583450 
previa pueda tener un verdadero alcance emancipatorio es necesario cuestionar desde una perspectiva crítica el fuerte sesgo colonial que arrastra este instrumento para afectos de desafiar la paradoja inclusión/exclusión en la que se encuentra inmersa. Con ese fin, es necesario interrogar la forma en que se están reproduciendo los legados coloniales que arrastra dicha institución tanto a través de su enseñanza en las facultades de derechos como de su ejercicio por parte de los operadores jurídicos, y repensarlos. Esto con el propósito de que los pueblos y comunidades puedan avanzar en la protección de sus territorios a través de instituciones como la consulta, y no solo en términos legales 'restringidos', sino en términos políticos.

Lo anterior implica que las comunidades cuenten con los medios que les permitan participar efectivamente en la definición de la agenda del diálogo que propone la consulta, que esta sea percibida como un auténtico encuentro entre iguales, y que los pueblos puedan discutir en el desarrollo del proceso de consulta temas que sean de su genuino interés y que suelen ser excluidos, tales como la territorialidad, la autodeterminación o el modelo de desarrollo económico que quieren o el que se les pretende imponer. En síntesis, cuestionar la consulta desde una mirada decolonial tanto en las aulas de clase como en los tribunales implica repensar no solo la episteme occidental que subyace a dicha institución en términos sustanciales, sino las condiciones y términos del diálogo per se que propone la consulta ${ }^{133}$.

\section{REFERENCIAS}

Alimonda, H. (2012). Una introducción a la ecología política. En Grosfoguel, R. y Almanza-Hernández, R. (eds.), Lugares descoloniales. Espacios de intervención en las Américas. Bogotá: Pontificia Universidad Javeriana.

Alimonda, H. (2011). La colonialidad de la naturaleza. Una aproximación a la ecología política latinoamericana. Alimonda, H. (coord.), La naturaleza colonizada. Ecología política y minería en América Latina. Clacso.

Antony Anghie. (2005). Imperialism, sovereignty, and the making of international law. Cambridge, UK: Cambridge University Press.

BArReto, J. M. (2012). Imperialism and decolonization as scenarios of human rights. En Barreto, J. M. (ed.), Human Rights from a Third World Perspective: Critique, History and International Law. Cambridge: Cambridge University Press.

Bermúdez-Liévano, A. La minera que quería tumbar el parque amazónico, La Silla Vacía, 2014. Disponible en: http://lasillavacia.com/historia/la-minera-que-estaba-detras-dela-tutela-al-parque-amazonico-46563

133 Gigenna A-I. Lecturas poscoloniales y decoloniales de la analítica foucaultiana para el análisis en contextos de herencia colonial. Confluenze. Rivista di studi iberoamericani, 2011, $3: 2$. 
Caso Cosigo Resources Ltd., Cosigo Resources Sucursal Colombia and Tobie Mining and Energy, Inc., (Investors) v. The Republic of Colombia (Respondent). Disponible en: http://www.italaw.com/sites/default/files/case-documents/italaw7172.pdf

Clavero, B. (2007). El orden de los poderes. Historias constituyentes de la trinidad constitucional. Madrid: Trotta.

Corte Constitucional Colombiana. Sentencia C-222 de 1995.

Corte Constitucional Colombiana. Sentencia SU-039 de 1997.

Corte Constitucional Colombiana. Sentencia T-652 de 1998.

Corte Constitucional Colombiana. Sentencia C-617 de 2008.

Corte Constitucional Colombiana. Sentencia T-769 de 2009.

Corte Constitucional Colombiana. Sentencia T-384A de 2014.

Corte Interamericana de Derechos Humanos. Caso Saramaka vs Suriname, 2007. Disponible en: http://www.corteidh.or.cr/docs/casos/articulos/seriec_172_ing.pdf

Corte Interamericana de Derechos Humanos. Medidas Cautelares en favor de la Comunidad del Alto Guayabal-Coredocito del Pueblo Emberá, Colombia, [2010] MC 12-09. Disponible en: http://www.oas.org/es/cidh/decisiones/cautelares.asp.

Constitución Política de 1991

Convenio 169 de la orT.

Comisión Colombiana de Juristas. "Urrá II”, una amenaza mortal para el pueblo indígena Embera Katío del alto Sinú (2008). Disponible en: http://www.coljuristas.org/documentos/boletines/bol_n22_975.pdf

Declaración de las Naciones Unidas sobre los derechos de los pueblos indígenas. Resolución aprobada por la Asamblea General, 61/295.

Declaración pública del Relator Especial sobre los Derechos Humanos y Libertades Fundamentales de los Indígenas, James Anaya, sobre la Ley del Derecho a la Consulta Previa a los Pueblos Indígenas u Originarios reconocido en el Convenio n. ${ }^{\circ} 169$ de la Organización Internacional de Trabajo, aprobada por el Congreso de la República del Perú 7 de julio de 2010. Disponible en: http://unsr.jamesanaya.org/statements/ declaracion-sobre-la-ley-del-derecho-a-la-consulta-previa-a-los-pueblos-indigenasperu-7-julio-2010

Departamento Administrativo Nacional de Estadística - DANE. Colombia, una nación multicultural. Su diversidad étnica. DANE, 2007. Disponible en: http://www.dane.gov. co/files/censo2005/etnia/sys/colombia_nacion.pdf

De Sousa Santos, B. (2006). Conocer desde el Sur. Lima: Universidad Nacional Mayor de San Marcos. 
Dussel, E. (2012). Las Casas. Vitoria and Suárez, 1514-1617. En Barreto, J. M. (ed.), Human Rights from a Third World Perspective: Critique, History and International Law. Cambridge: Cambridge University Press.

EsLava, L. Constitutionalization of Rights in Colombia: Establishing a ground for meaningful comparisons. Revista Derecho del Estado, Universidad Externado de Colombia. N. ${ }^{\circ} 22,2009$. Disponible en: http://revistas.uexternado.edu.co/index.php/derest.

Escobar, A. Conversaciones sobre el Sur global: gobernanza, extractivismo y resistencia. Conferencia. Bogotá: Universidad del Rosario, 24 de agosto de 2015. Disponible en: http://www.urosario.edu.co/Home/Principal/Eventos/Facultad-de-Jurisprudencia/ Conversaciones-sobre-el-Sur-Global/

Escobar, A. Hay que abandonar la idea afanosa del crecimiento. El Espectador, 2 de septiembre de 2015. Disponible en: http://www.elespectador.com/noticias/economia/ hay-abandonar-idea-afanosa-del-crecimiento-economico-articulo-583450

FAnon, F. (1961). Los condenados de la tierra. México: Fondo de Cultura Económica, 1983. (Título original: Les damnés de la terre). Paris: Maspero.

Gigenna Andrea-Ivanna. (2011). Lecturas poscoloniales y decoloniales de la analitica foucaultiana para el análisis en contextos de herencia colonial. Confluenze. Rivista di studi iberoamericani, 3:2.

Grosfoguel, R. (2006). La descolonización de la Economía Política y los Estudios Postcoloniales: transmodernidad, pensamiento fronterizo y colonialidad global. Tabula Rasa. 4.

Grosfoguel, R. y Castro-Gómez, S. (2007). Giro decolonial, teoría crítica y pensamiento heterárquico. En Castro-Gómez, S. y Grosfoguel, R. (eds.). El giro decolonial: reflexiones para una diversidad epistémica más allá del capitalismo global. Bogotá: Siglo del Hombre Editores, Universidad Central y Universidad Javeriana.

Grosfoguel, R. y Almanza-Hernández, R. (eds.) (2012). Lugares descoloniales. Espacios de intervención en las Américas. Bogotá: Pontificia Universidad Javeriana.

Grosfoguel, R. (2012). Colonialidad del poder y dinámica racial. Notas para la interpretación de los latino-caribeños en Nueva York. En Grosfoguel, R. y Almanza-Hernández, R. (eds.), Lugares descoloniales. Espacios de intervención en las Américas. Bogotá: Pontificia Universidad Javeriana.

Grosfoguel, R. (2005). The Implications of Subaltern Epistemologies for Global Capitalism: Transmodernity, Border Thinking and Global Coloniality. En Appelbaum, R. P. y Robinson, W. I. (eds.), Critical Globalization Studies. Routledge.

Grosfoguel, R. (2011). Decolonizing Poscolonial Studies and Paradigms of Political Economy: Transmodernity, decolonial thinking and Global Coloniality. Journal of Peripheral Cultural Production of the Luso-Hispanic World 1.1, 21-23.

Grosfoguel, R. Developmentalism, Modernity and Dependency Theory in Latin America. En Coloniality at large: Latin America and the Postcolonial Debate. Duke University Press, 2008. 
Gudynas, E. (2011). Desarrollo, derechos de la naturaleza y buen vivir después de Montecristi. En Weber, G. (ed.). Debates sobre cooperación y modelos de desarrollo, Perspectivas desde la sociedad civil en el Ecuador. Quito: Centro de Investigaciones CIUDAD y Observatorio de la Cooperación al Desarrollo.

Hall, S. (1996). When was the post-colonial? Thinking at the Limit. En Chambers, I. y CurTI, L. The post-colonial question: Common skies, divided horizons. Routledge.

Hernández Zubizarreta, J. (2009). ¿"Lex mercatoria" o derechos humanos? Los sistemas de control de las empresas transnacionales. En Hernández Zubizarreta, J. y Ramiro, P. (eds). El negocio de la responsabilidad. Crítica de la Responsabilidad Social Corporativa de las empresas transnacionales. Icaria.

La Silla Vacía. La minera que quería tumbar el parque amazónico, 2014. Disponible en: http://lasillavacia.com/historia/la-minera-que-estaba-detras-de-la-tutela-al-parqueamazonico-46563.

Lemaitre Ripoll, J. (2009). El derecho como conjuro. Fetichismo legal. Violencia y movimientos sociales. Bogotá: Siglo del Hombre Editores.

Machado Aráoz, H. (2011). El auge de la minería transnacional en América Latina. De la ecología política del neoliberalismo a la anatomía política del colonialismo. En Alimonda, H. (coord.), La naturaleza colonizada. Ecología política y minería en América Latina. Clacso.

Mazariegos, M. Derecho a la consulta y disenso. Por el uso contra hegemónico del derecho. Tesis de doctorado, Universidad Carlos III de Madrid, 2014. Disponible en: http://e-archivo.uc3m.es/bitstream/handle/10016/19134/monica_mazariegos_tesis. pdf?sequence $=1$

Medio Ambiente, Redacción. Minera Cosigo no pudo tumbar el Parque Apaporis. El Espectador (2015). Disponible en: http://www.elespectador.com/noticias/medio-ambiente/ minera-cosigo-no-pudo-tumbar-el-parque-apaporis-articulo-583189.

Merino, R. (2015). Coloniality and Indigenous Territorial Rights in the Peruvian Amazon: A Critique of the Prior Consultation Law. Bath Papers in International Development and Wellbeing Centre for Development Studies, 38. University of Bath.

Mignolo, W. (2003). Historias locales/diseños globales. Madrid: Akal.

Misión Humanitaria de Verificación (Organización Indígena de Antioquia - OIA; Oficina del Alto Comisionado de las Naciones Unidas para los Refugiados - ACnUR; Oficina de Derechos Humanos de la Organización de las Naciones Unidas -onu; Defensoría del Pueblo Regional Urabá; la Organización No Gubernamental Brigadas de Paz - PBI; Organización No Gubernamental Justicia y Paz; Organización Nacional Indígena de Colombia - onic; Guardia Indígena del Resguardo de Polines y Chigorodó). Informe Misión Humanitaria de Verificación Comunidad Indígena Embera Katio de Alto Guayabal-Urada Jiguamiandó (Carmen del Darién, Antioquia-Chocó, 2010). Disponible en: www.onic.org.co/img_upload/3068e9df14b050d72c4fa19fabbab2d7/ INFORME _ URADA.dOC

Pahuja, S. (2013). Laws of encounter: A jurisdictional account of international law. 1:1 London Review of International Law. 
Peace Brigades International, PBI Project Colombia. Proyecto Mandé Norte sigue en pie (2011). Disponible en: http://www.pbi-colombia.org/field-projects/pbi-colombia/newsfrom-colombia/news/?tx_ttnews\%5Btt_news $\% 5 \mathrm{D}=2628 \& \mathrm{cHash}=\mathrm{bf} 399 \mathrm{~b} 6882 \mathrm{f} 8 \mathrm{dc} 82 \mathrm{~b}$ de42ddb9808dbde.

Polanyi, K. (2007). La gran transformación. Crítica del liberalismo económico. Quipu Editorial.

Orduz-Salinas, N. y Rodríguez-Garavito, C. (2012). Adiós río. La disputa por la tierra, el agua y los derechos indígenas en torno a la represa de Urrá. Disponible en: https:// justiciaambientalcolombia.org/2012/09/27/nuevo-libro-de-dejusticia\%E2\%80\%8Badios-rio-la-disputa-por-la-tierra-el-agua-y-los-derechos-indigenas-en-torno-a-larepresa-de-urra/

Quijano, A. (2000). Coloniality of power and Eurocentrism in Latin America. International Sociology 15.2.

Quijano, A. y Wallerstein, I. (1992). Americanity as a concept; or, The Americas in the modern world. International Social Science Journal 134.

Rodríguez, G. A. (2014). De la consulta previa al consentimiento libre, previo e informado a pueblos indígenas en Colombia. Bogotá: Universidad del Rosario, GIz, Cooperación Alemana.

Silva-Herrera, J. (2014). Tres magistrados van a la selva; evalúan si permiten extracción de oro. El Tiempo. Disponible en: http://www.eltiempo.com/archivo/documento/ CMS-13427338.

SuÁREZ-RicAurte, F. El derecho a la consulta previa de las comunidades indígenas, étnicas y tribales y la minería en Colombia. Una lectura a partir del derecho al territorio indígena. En Minería y desarrollo. Bogotá: Universidad Externado de Colombia, 2016.

Torres-Maldonado, N. (2011). Thinking through the Decolonial Turn: Post-continental Interventions in Theory, Philosophy, and Critique. An Introduction. Journal of Peripheral Cultural Production of the Luso-Hispanic World 1.2.

Velásquez-Ruiz, M. (2016). Al que no quiere caldo: Tobie Mining Inc. demanda a Colombia por 16.5 billones de dólares. Disponible en: http://blogs.eltiempo.com/desmarcado/2016/03/22/tobie-mining-demanda-colombia/ 